Article

\title{
Functions of the Thyroid-Stimulating Hormone on Key Developmental Features Revealed in a Series of Zebrafish Dyshormonogenesis Models
}

\author{
Jia Song ${ }^{1,2} \mathbb{D}$, Yao Lu ${ }^{1,2}{ }^{\text {, Xiaoxia Cheng }}{ }^{3}$, Chuang Shi ${ }^{1}$, Qiyong Lou ${ }^{1}$, Xia Jin ${ }^{1}$, Jiangyan He ${ }^{1}$, Gang Zhai ${ }^{1,2, *}$ \\ and Zhan Yin $1,2, *$ \\ 1 State Key Laboratory of Freshwater Ecology and Biotechnology, Institute of Hydrobiology, \\ Chinese Academy of Sciences, Wuhan 430072, China; songjia@ihb.ac.cn (J.S.); luyao@ihb.ac.cn (Y.L.); \\ shichuang@ihb.ac.cn (C.S.); louqiyong@ihb.ac.cn (Q.L.); jinxia@ihb.ac.cn (X.J.); jyhe@ihb.ac.cn (J.H.) \\ 2 College of Advanced Agricultural Sciences, University of Chinese Academy of Sciences, Beijing 100049, China \\ 3 Key Laboratory of Receptors-Mediated Gene Regulation and Drug Discovery, \\ School of Basic Medical Sciences, Henan University, Kaifeng 475004, China; 10190130@vip.henu.edu.cn \\ * Correspondence: zhaigang@ihb.ac.cn (G.Z.); zyin@ihb.ac.cn (Z.Y.)
}

Citation: Song, J.; Lu, Y.; Cheng, X.; Shi, C.; Lou, Q.; Jin, X.; He, J.; Zhai, G.; Yin, Z. Functions of the ThyroidStimulating Hormone on Key Developmental Features Revealed in a Series of Zebrafish Dyshormonogenesis Models. Cells 2021, 10, 1984. https:// doi.org/10.3390/cells10081984

Academic Editor: Yusuke Kamachi

Received: 6 June 2021

Accepted: 29 July 2021

Published: 4 August 2021

Publisher's Note: MDPI stays neutral with regard to jurisdictional claims in published maps and institutional affiliations.

Copyright: (c) 2021 by the authors. Licensee MDPI, Basel, Switzerland. This article is an open access article distributed under the terms and conditions of the Creative Commons Attribution (CC BY) license (https:// creativecommons.org/licenses/by/ $4.0 /)$.

\begin{abstract}
The hypothalamic-pituitary-thyroid (HPT) axis regulates many critical features in vertebrates. Utilizing TALENs and CRISPR/Cas9 techniques, thyroid-stimulating hormone subunit beta a (tshba), thyroglobulin ( $t g)$, and solute carrier family 16 member 2 (slc16a2) mutant zebrafish lines were generated. Among the three mutants, the earliest time point for the significantly altered T3 contents was observed in tshba mutants, which resulted in the most severe defects, including typical defects such as the retardation of inflated anterior swimming bladder (aSB), proper formation of fin ray and posterior squamation (SP), the larval-to-juvenile transition (LTJT) process, juvenile growth retardation, and mating failure. In $t g$ mutants, which are actually compensated with an alternative splicing form, growth retardation was observed in the juvenile stage without LTJT and reproductive defects. The evident goiter phenotype was only observed in $t g$ - and slc16a2 mutants, but not in $t s h b a$ mutants. Other than goiters being observed, no other significant developmental defects were found in the slc16a2 mutants. Regarding the reproductive defects observed in tshba mutants, the defective formation of the secondary sex characteristics (SSCs) was observed, while no obvious alterations during gonad development were found. Based on our analyses, zebrafish at the 6-12 mm standard length or 16-35 days post-fertilization (dpf) should be considered to be in their LTJT phase. Using a series of zebrafish dyshormonogenesis models, this study demonstrated that the TSH function is critical for the proper promotion of zebrafish LTJT and SSC formation. In addition, the elevation of TSH levels appears to be essential for goiter appearance in zebrafish.
\end{abstract}

Keywords: thyroid-stimulating hormone; thyroglobulin; slc16a2; larval-to-juvenile transition; goiter; secondary sex characteristic

\section{Introduction}

The thyroid hormone (TH) controls different processes in vertebrates, including metamorphosis, oxidative metabolism, and annual change of the photoperiod [1-4]. Although the specifics may differ, the mechanisms and compositions of the hypothalamic-pituitarythyroid (HPT) axis in vertebrates are relatively conserved. Thyroid hormonogenesis is regulated via thyrotropin-releasing hormone (TRH) and thyroid-stimulating hormone (TSH), and circulating triiodothyronine (T3) and thyroxine (T4) can act as dynamic negative feedback signals for the hypothalamus and pituitary to regulate the levels of TH via the production of TRH and TSH. Therefore, TSH, a heterodimer protein of two glycoprotein hormone subunits $\alpha$ and $\beta$, both of which are secreted from the anterior lobe of the pituitary gland, is a major signal that plays a positive regulatory role in thyroid homeostasis. The $\alpha$ 
subunit is common to the three pituitary glycoprotein hormones, whereas the $\beta$ subunit is TSH-specific, providing receptor specificity $[5,6]$. In thyroid follicular cells, thyroglobulin (TG) is a large dimeric protein that is required for TH synthesis, storage, and secretion processes. THs, including T4 and T3, have iodine atoms. After TH synthesis in the thyroid gland, solute carrier family 16 member 2 (SLC16A2) (also named monocarboxylate transporter 8) is a specific TH transporter in certain tissues that allows the cellular entry of THs to access their nuclear receptors for downstream $\mathrm{TH}$ signaling activation.

Nearly $10 \%$ of the human population may be at risk of developing a thyroid-related disease during their lifetime, such as central congenital hypothyroidism $(\mathrm{CCH})$, goiter, and Allan-Herndon-Dudley syndrome (AHDS) [7-9]. Certain types of mutations of the $\mathrm{tshb}, \mathrm{tsh}$, tg, slc16a2, solute carrier $5 a 5$ (slc5a5), dual oxidase 2 (duox2) genes, etc., have been reported to be associated with these congenital diseases [9-15]. To allow the investigation of the pathophysiological mechanisms of various types of these disorders, several animal models have been generated. With convenient targeted genetic procedures, zebrafish have emerged as a fascinating vertebrate animal model for biomedical studies. The AA sequence of Tshb in zebrafish is highly similar to that of the mammalian TSH $\beta$ molecule, especially at its critical domains [16]. However, the role of TSH in teleost fish, especially during post-embryonic stages, remains uncertain due to the lack of a relevant genetic model. TG is a large dimeric glycoprotein required for TH synthesis in vertebrate thyrocytes. The reported human monomer TG molecular mass is $330 \mathrm{kDa}$, containing nearly 2750 AA residues, comprising type I, II, and III repeat motif-containing regions and the C-terminal cholinesterase-like domain [17]. Patients and rodent models with $t g$ gene mutations typically develop hypothyroidism goiters $[18,19]$. However, it is possible that certain weak genetic variations within the $\mathrm{tg}$ locus contribute to euthyroid familial goiters. Beside mammals, available $\mathrm{Tg}$ sequences have been identified in teleost genomes; for example, a putative zebrafish $\mathrm{Tg}$ contains 2733 AAs reported previously [20]. Zebrafish $\mathrm{Tg}$ levels are commonly used as an indicator for endogenous TH synthesis activity [21]. However, the physiological importance of fish $\mathrm{Tg}$ protein is yet to be experimentally investigated. Patients with SLC16A2 mutations exhibit psychomotor deficits associated with Allan-Herndon-Dudley syndrome (AHDS) [8], with rare cases also exhibiting goiter, while no apparent brain development and neurological defects have been observed in Slc16a2 mutant mice [22,23]. Intriguingly, mutations in the zebrafish slc16a2 gene cause neurological and behavioral phenotypical changes in larvae, which makes zebrafish an emerging model for exploring the process of TH signaling in the presence of psychomotor defects. However, little information is currently available regarding the syndromes of the slc16a2 mutant zebrafish during their adult stage, including goiter [24]. Several other homozygous gene-deficient germline zebrafish models related to TH signaling have been established, including deiodinase type 2 (dio2), organic anion-transporting polypeptide 1c1 (oatp1c1, also known as slco1c1), dual oxidase (duox), and thyroid hormone receptor $a$ and $b$ (thra and thrb). Like the slc16a2 mutant model, oatp1c1 deficiency causes neural alterations and hyperactivity of the HPT axis activity in mutant larvae and adults. Goiter has been observed in oatp1c1and slc16a2-deficient zebrafish [25]. NADPH oxidase DUOX generates hydrogen peroxide, which is a crucial electron acceptor during thyroid peroxidase-catalyzed iodination and coupling reactions during the TH synthesis process. DUOX-deficient zebrafish exhibit observable phenotypes reminiscent of human $\mathrm{CCH}$, including growth retardation and goiter. Besides, delayed initiation of anterior swim bladder (aSB) development, one of the major features in larval-to-juvenile transition (LTJT) in zebrafish, has also been observed in duox-deficient zebrafish [26]. Most recently, studies on the deficiency of Thra in zebrafish indicate that decreased TH levels and impaired post-larval growth and skin development occur in thrab mutant zebrafish [27].

Here, $t s h b, t g$, and slc16a2 mutant zebrafish models were generated using TALENs and CRISPR/Cas9 techniques. The observable changes in dynamics of whole-body TH contents were recorded in all three mutant zebrafish types and compared with those of their control fish siblings. In particular, significantly decreased TH levels were observed 
25 days post-fertilization (dpf) in $t s h b$ mutant zebrafish, and $60 \mathrm{dpf}$ in $t g$ mutant zebrafish. Interestingly, impaired development of the features of LTJT and reproductive activities in zebrafish was only found in the tshba mutants, which is relevant to the early initiation of the dyshormonogenesis observed at the larval stage in tshba mutants. Both tshba and tg mutant fish displayed growth retardation with various extensions during the juvenile stage initially. They eventually reached their normal size during their adult stage. In addition, adulthood goiter phenotypes were only observed in $\operatorname{tg}$ and slc16a2 mutant zebrafish, indicating the critical role of TSH in thyrocyte proliferation and its involvement in the negative regulatory network through endogenous TH levels. These mutant zebrafish provided a series of teleost models for understanding the regulatory functions of TH signaling in animal development further.

\section{Materials and Methods}

\subsection{Zebrafish Maintenance and Treatment}

All zebrafish ( $\mathrm{AB}$ strain and $t s h b a$, $t g$, and slc16a2 mutants generated using $\mathrm{AB}$ strain) were maintained in a circulating water system with a $14 \mathrm{~h} \mathrm{light}$ and $10 \mathrm{~h}$ dark cycle at $28.5^{\circ} \mathrm{C}$ and were fed twice daily with newly hatched brine shrimp (Artemia salina). The procedure for fish maintenance followed that of a previous study [28]. All fish experiments were conducted in accordance with the Guiding Principles for the Care and Use of Laboratory Animals and were approved by the Institute of Hydrobiology, Chinese Academy of Sciences (Approval ID: IHB2013724).

For T3 treatment, the crossed progeny of tshba heterozygote mutants were used. Larvae were reared in a $1 \mathrm{~L}$ tank at a density of 30 larvae per tank. The water in each $1 \mathrm{~L}$ tank was replaced daily. Stock solutions of T3 (T2877, Sigma-Aldrich, St Louis, MO, USA) were initially dissolved in dimethyl sulfoxide (DMSO) then diluted in water for the experimental treatments. The final DMSO concentrations were below $0.1 \%$. Larvae were treated with $2.5 \mu \mathrm{g} / \mathrm{L}$ of T3 for rescue, starting at $12 \mathrm{dpf}$. The control larvae were exposed to DMSO. T3-treated larvae were sampled and analyzed at different stages.

\subsection{Establishment of Mutant Lines}

The tshba mutant line was obtained using the TALEN gene targeting technique as previously described [29]. Specific TALEN target sites were designed and located on the third exon of the zebrafish tshba gene. Paired TALENs were constructed with the Golden Gate TALEN Kit [30]. TALEN mRNAs $(100 \mathrm{ng} / \mu \mathrm{L})$ were microinjected into the one-cell stage wild-type zebrafish embryos. For tshba mutation screening, the target genomic regions were amplified by PCR reaction with gene-specific primers and digested with $\mathrm{BtsCI}$ restriction enzymes, which is located within the targeting region of tshba. The digested PCR products were separated by electrophoresis using a $1 \%$ agarose gel.

The $t g$ and slc16a2 mutant lines were generated using the CRISPR/Cas9 system as previously described [31]. Specific guide RNA (gRNA) target sites located at the fourth exon of the $\operatorname{tg}$ gene ( $\operatorname{tg}$ gRNA sequences: $5^{\prime}$-GACTCAGGTGAGTACCAGCAGG-3') and first exon of the slc16a2 gene (slc16a2 gRNA sequences: $5^{\prime}$-GGAGTCCTCTTCCCCTGCG GAGG-3') were selected, and gRNA was transcribed with the TranscriptAid T7 High-Yield Transcription Kit (Thermo Fisher Scientific, Waltham, MA, USA). For Cas9 messenger RNA (mRNA) synthesis, pXT7-humanized Cas9 expression vector was linearized with XbaI restriction enzymes, purified, and transcribed using mMESSAGE mMACHINE T7 Ultra Kit (Ambion, Carlsbad, CA, USA) according to the manufacturer's instructions. A mixture of Cas 9 mRNA ( $300 \mathrm{ng} / \mu \mathrm{L})$ and gRNA $(20 \mathrm{ng} / \mu \mathrm{L})$ was then co-injected into one-cell stage zebrafish embryos. A PAGE-based genotyping assay was conducted to examine the mutation of the $\operatorname{tg}$ or slc16a2 gene as previously described [32]. Briefly, the target genomic regions of each individual were amplified by a standard PCR reaction with gene-specific primers. The PCR products were denatured at $95^{\circ} \mathrm{C}$ for $10 \mathrm{~min}$ to form heteroduplexes and were then loaded into a 10\% polyacrylamide gel with the running condition of $220 \mathrm{~V}$ for $1.5 \mathrm{~h}$. 
To obtain germline mutations of $t s h b a$, $t g$, and slc16a2 genes, the F0 generation zebrafish were raised to adulthood and mated with wild-type fish to generate heterozygous F1 offspring. The heterozygous F1 generation fish were genotyped via the assay mentioned above and confirmed by sequencing. The individuals with frame-shift sequence alterations were selected. Males and females of the F1 generation carrying the same mutation were mated to produce F2 homozygous mutants, which were genotyped via BstCI digestion or PAGE assay. The specific primers used for PCR genotyping are listed in Supplementary Table S1.

\subsection{RNA Extraction and $q P C R$}

Total RNA was extracted using TRIzol reagent, and cDNA was synthesized using an oligo (dT) 18 primer and a RevertAid First Strand cDNA Synthesis Kit (Thermo Fisher Scientific, Rockford, IL, USA) according to the manufacturer's instructions. The gene-specific qPCR primers were designed using the National Center for Biotechnology Information (NCBI) primer BLAST service and are listed in Supplementary Table S1. All mRNA levels were calculated as fold-expression levels relative to the housekeeping gene eukaryotic translation elongation factor 1 alpha. Each sample was run in triplicate, and the results were expressed according to a previously described method [33]. The primers for qPCR (Supplementary Table S1) were validated by DNA sequencing and agarose gel electrophoresis of the PCR products. The qPCR was performed using the TransStart TIP Green qPCR SuperMix Kit (AQ141, Transgene Biotech, Beijing, China) according to the manufacturer's instructions. qPCR cycling conditions were: $95^{\circ} \mathrm{C}$ for $5 \mathrm{~min}\left[95^{\circ} \mathrm{C}\right.$ for $15 \mathrm{~s}, 60^{\circ} \mathrm{C}$ for $15 \mathrm{~s}$, $72{ }^{\circ} \mathrm{C}$ for $15 \mathrm{~s}$ ] ( 45 cycles), $95^{\circ} \mathrm{C}$ for $60 \mathrm{~s}$, followed by dissociation curve analysis.

\subsection{Whole-Mount Immunofluorescence}

Whole-mount immunofluorescence was carried out as described previously $[26,34]$. Briefly, more than 60 zebrafish larvae at $5 \mathrm{dpf}$ derived from the mating of heterozygous tshba parents after treatment, were incubated at $4{ }^{\circ} \mathrm{C}$ in blocking buffer containing the primary antibody against T4 (1:1000 dilution, polyclonal rabbit anti T4, 08658501, MP Biomedicals, LCC, Illkirch, France). After several wash steps in PBST containing 1\% BSA, larvae were then incubated overnight at $4{ }^{\circ} \mathrm{C}$ in blocking buffer containing the secondary antibodies (1:250 dilution, goat anti-rabbit IgG-FITC, SA00001, Proteintech Group, Chicago, IL, USA). Fluorescent images were taken of all the stained larvae. Next, the larvae were washed in PBST and subjected to genotyping. Based on the results of genotyping, all images from the homozygous tshba mutants and wild-type larvae were grouped for fluorescent intensity quantification. For each embryo, the ventral view of the heads was obtained following a previously described protocol [26,34] using Image software (National Institutes of Health, Bethesda, MD, USA). Integrated density was selected as the parameter for measuring fluorescence inside the thyroid follicles, which was conducted using the "Integrated Density" tool of ImageJ software.

\subsection{Protein Extraction and Western Blot Analysis}

For Western blots, the heads were dissected from the $5 \mathrm{dpf}$ zebrafish larvae. Heads from 12-15 larvae were pooled and homogenized in lysis buffer containing proteinase inhibitors $(1 \%, v / v)$, a phosphatase inhibitor $(0.1 \%, v / v)$, and phenylmethanesulfonyl fluoride $(1 \%$, $v / v)$. Protein concentrations were measured by the Bradford method [35]. Approximately $40 \mu \mathrm{g}$ of each protein sample were loaded into a Tris-glycine $10 \%$ polyacrylamide gel. After electrophoresis, proteins were electro-transferred onto nitrocellulose membranes. Membranes were probed with the primary antibodies against TG (polyclonal rabbit anti-human TG, IR509, Dako, Carpinteria, CA, USA) overnight at $4{ }^{\circ} \mathrm{C}$ and incubated with HRP-conjugated secondary antibodies at $37^{\circ} \mathrm{C}$ for $2 \mathrm{~h}$. After several wash steps in Tris-buffered saline Tween 20, the blots were developed using an ECL reagent (P90720, Millipore, Billerica, MA, USA). Using a rabbit anti-human TG serum antibody, Western blotting detected a single protein of $\sim 260 \mathrm{kDa}$ for TG. Bands on autoradiographs were quantified by densitometry. 


\subsection{Analyses of Growth and Developmental Timing}

The crossed progeny of the heterozygote mutants were used for analyses of postembryonic growth and development. Fish from the crossed clutch were isolated at $10 \mathrm{dpf}$ and reared individually in water-filled plastic cups, the water of which was changed daily. Each individual was anesthetized briefly with tricaine (MS222) and was immersed in 1\% methylcellulose. Fish were imaged daily from 10 to $30 \mathrm{dpf}$ and every three days from 33 to $60 \mathrm{dpf}$ using an Olympus SZX-16 epifluorescence stereomicroscope (Olympus Corp., Tokyo, Japan). Images were further processed to evaluate post-embryonic growth and development. Each fish was genotyped at $60 \mathrm{dpf}$. To analyze post-embryonic growth, images were measured in Image for standard length (SL) and staged according to external anatomical features [36]. Differences in the age and SL between wild-type and mutants upon reaching defined stages of post-embryonic development were analyzed by ANOVAs to test the effects of genotypes, developmental stages, and phenotypes on the two groups.

\subsection{Thyroid Hormone Quantification}

Since the size of zebrafish is small, the levels of T3 and T4 in the whole body were quantified with the liquid chromatography-quadrupole time-of-flight mass spectrometry (LC-MS/MS) method as described previously [37]. Three groups of fish were sampled at different stages of development. The fish were genotyped individually with the genomic DNA of the tail fin. The numbers of individuals used in each group for the time points of 16, 20, 25, 30, and $60 \mathrm{dpf}$ were $40,20,8,4$, and 2 fish as a sample, respectively. The triplicate samples were then pooled in pre-weighed microcentrifuge tubes and wet weights were recorded. The samples were stored at $-80{ }^{\circ} \mathrm{C}$ for the quantification of TH levels. TH was extracted from the samples then analyzed by UPLC-MS/MS (Xevo TQ-S Triple Quadrupole Mass Spectrometry, Waters, Milford, MA, USA), following a previously described method [38].

\subsection{Behavioral Assays}

Behavioral tests were conducted using a ZebraBox system (ViewPoint Life Sciences, Lyon, France). To measure swimming ability, each test fish was placed into a separate Petri dish with $10 \mathrm{~mL}$ of water. Twelve fish were tested from each group. The swimming behavior tests were recorded for $10 \mathrm{~min}$ from the dorsal viewpoint of the dish. The resulting data were analyzed using ZebraBox software (Viewpoint Life Science, Lyon, France). To measure mating behavior, the mating process in a spawning tank was recorded. The videos started $5 \mathrm{~min}$ after removing the separators. The duration of the video for each pair was $5 \mathrm{~min}$. The mating behaviors were analyzed using ZebraBox software.

\subsection{Micro-CT Scan}

The fish at the $30 \mathrm{dpf}$ stage were euthanized with MS222 then fixed overnight in $4 \%$ PFA at $4{ }^{\circ} \mathrm{C}$. The samples were scanned under $\mathrm{X}$-ray with micro-CT visualization according to a previously described method. Briefly, the fixed sample was placed in a sample holder and observed using a micro-CT (SkyScan 1276 micro-CT system, Bruker, Kontich, Belgium) with an X-ray source of $42 \mathrm{kV}$ and a $200 \mu \mathrm{A}$ current. A high-resolution camera was used with a $0.4-0.7{ }^{\circ} \mathrm{C}$ rotation pitch and a $3.0 \mu \mathrm{m}$ image resolution. In total, 1027 projection images were recorded within $10 \mathrm{~min}$ of exposure time. Images were reconstructed and analyzed with CTvox software provided by the manufacturer.

\subsection{Statistical Analysis}

Detailed information regarding the number of zebrafish used in each experiment has been provided in all figure legends. All analyses were performed using GraphPad Prism 5.0 software (GraphPad Software Inc., San Diego, CA, USA), and the differences were assessed using Student's $t$-test. The results are expressed as the mean \pm SEM. For all statistical comparisons, $p<0.05$ was used to indicate a statistically significant difference. 


\section{Results}

\subsection{Generation of Tshba Mutant Zebrafish}

In zebrafish, TSH $\beta$ was encoded by the tshba gene located at chromosome 6 . To investigate the potential functions of tshba in zebrafish, the zebrafish tshba locus was targeted using the TALENs technique. Mutant fish with a 5 bp deletion in the third exon of the tshba gene of the tshba locus was achieved (Figure 1A).

The F2 progenies were screened using BtsCI restriction enzymes. The $\mathrm{BtsCI}$ digestion assay revealed that the fragments containing target sites of wild-type fish were completely cut into two smaller fragments, those of heterozygotes were cut partly, and those of homozygotes were not cut at all (Figure 1B). To confirm the mutations in the target region, PCR-amplified cDNAs of homozygous mutants were sequenced. The results showed that the sequence of the tshba mutant gene carried a 5-nucleotide deletion and a singlenucleotide substitution $(\mathrm{G} \rightarrow \mathrm{C})$ on the tshba exon 3 (Figure $1 \mathrm{C}$ ). The cDNA carrying the $5 \mathrm{bp}$ deletion led to a putative premature termination of the Tshb protein at AA position 145 , with 23 AAs different from the wild-type Tshb protein sequence at the C-terminus (Figure 1D).

The zebrafish TSH $\beta$ a protein was compared with the protein sequence of human $\mathrm{TSH} \beta$ protein and tshb $\mathrm{C} 105 \mathrm{~V}$ patients were identified that exhibited severe syndromes due to the last conserved cysteine being lost in the mutant human TSH $\beta$ protein, and damaged seat-belt structure [9] (Supplementary Figure S1A). The multi-alignment analysis of the TSH $\beta$ a proteins indicated the high similarity between our zebrafish tshba mutation and the human tshb $\mathrm{C} 105 \mathrm{C}$ mutation. There were significant discrepancies between the sequences of the zebrafish TSHba and TSHbb proteins (Supplementary Figure S1B). Additionally, in tshba mutants, significantly elevated tshba mRNA levels were found, but no compensative $t s h b b$ mRNA levels were observed, compared with those in the control fish (Figure 1B). All whole mount immunofluorescence experiments were conducted with 81 larvae at the $5 \mathrm{dpf}$ stage using T4 antibodies, which indicated that the immunoreactivity for T4 levels in tshba mutant larvae $(n=20)$ was considerably less than that in their wild-type siblings $(\mathrm{n}=21)$ (Figure $1 \mathrm{~F}, \mathrm{G})$. The mRNA expression levels of the key genes involved in TH synthesis in larvae at $5 \mathrm{dpf}$ were tested with quantitative RT-PCR. The results showed that the expression levels of tg, thyroid peroxidase (tpo), and slc5a5 genes were significantly downregulated in tshba mutant larvae compared to those in their wildtype siblings (Figure 1H). Western blot analysis showed that the level of TG protein was significantly downregulated in tshba mutant fish (Figure 1I,J). In terms of the impacts on pituitary hormone secretion, the expression levels of the $f s h b, l h b$, and pomca genes were significantly downregulated in the tsha mutant zebrafish at the $20 \mathrm{dpf}$ stage, compared with those in their wild-type siblings (Figure 1K).

To investigate the effect of the Tshba mutation on thyroid hormonogenesis in zebrafish, we measured the total TH content at different developmental stages using the LC-MS/MS method. There were no significant differences in either T4 or T3 contents between tshba mutants and their wild-type siblings before the $16 \mathrm{dpf}$ stage (Figure $1 \mathrm{~L}, \mathrm{M}$ ). However, significantly decreased T4 content in tshba mutants at $20 \mathrm{dpf}$ was observed, while the T3 content was not affected at this stage. The significant differences in both T4 and T3 contents between tshba mutants and their control siblings were increasingly evident after the $25 \mathrm{dpf}$ stage, with $\mathrm{T} 4$ depletions being more severe than $\mathrm{T} 3$ ones. These results suggest that the tshba mutation causes impairment of the dynamic endogenous TH production, which serves as a model for the fish CCH model. 
A

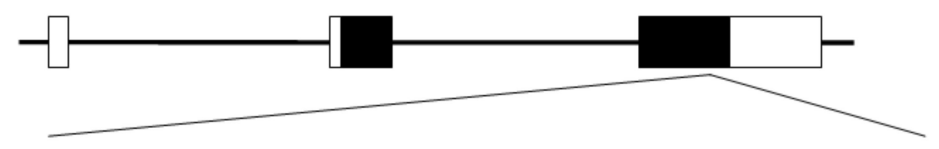

\section{$\longleftarrow$ Left-arm $\longrightarrow \quad$ BtsC I}

5' -AATGTGCCCTTAAAACCCGCAGCGCTGGGATGAGATGCTCCAAACCTGTGCATCATCTGTACCCC-3' 3' -TTACACGGGAATTTTGGGCGTCGCGACCCTACTCTACGAGGTTTGGACACGTAGTAGACATGGGG-5' $\longmapsto$ Right-arm $\longrightarrow \mid$

C

tshba +/+ GCCCTTAAAACCCGCAGCGCTGGGATGAGATGCTCCAAACCTGTGCATCATCTGT tshba-l- GCCCTTAAAACCCGCAGCGCTGGGA----A-CCTCCAAACCTGTGCATCATCTGT
B

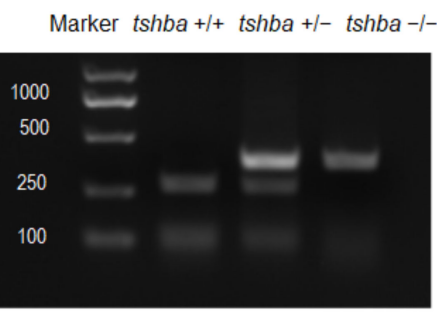

D

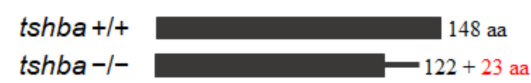

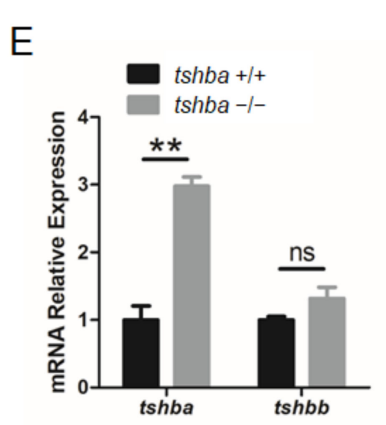

F

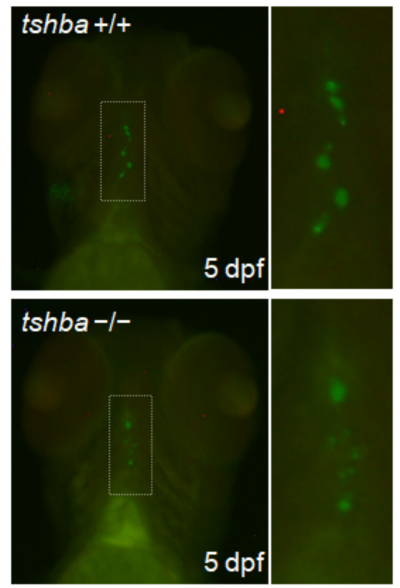

G

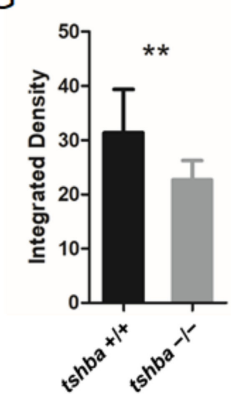

J

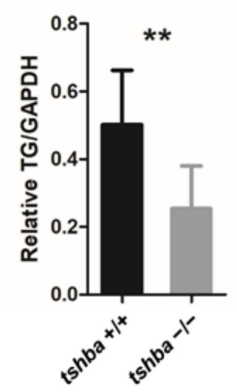

$\mathrm{K}$

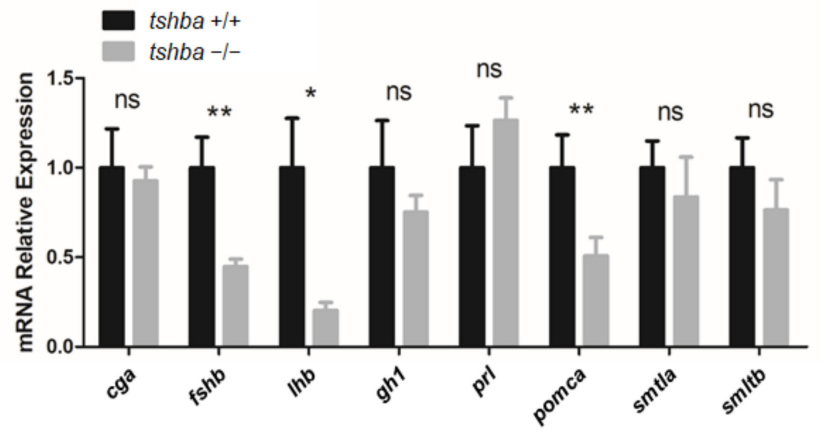

M

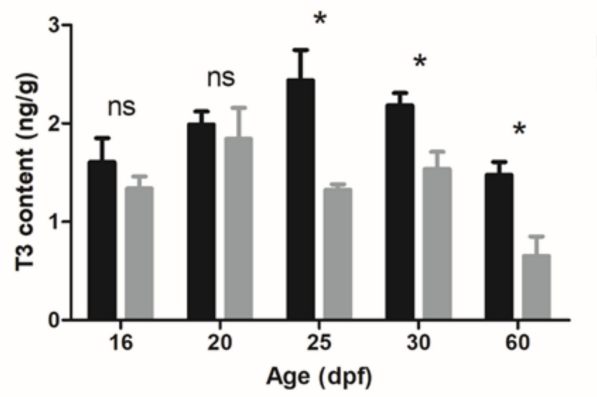

Figure 1. Generation of the tshba mutant zebrafish. (A) Schematic representation of the genomic structure of tshba and the targeting site on exon 3. The regions of the left and right arms are labeled above and below, respectively. The BtsCI site in the spacer is labeled above. (B) Genotyping of the tshba $+/+, t s h b a+/-$, and $t s h b a-/-$ individuals represented with the un-cleaved and cleaved PCR products is indicated. (C) DNA sequences of the targeting regions of the tshba locus in wild-type and tshba mutant zebrafish. (D) Predicted putative wild-type and mutant Tshba protein structures. The $5 \mathrm{bp}$ 
deletion generated a miscoded peptide after the 122th amino acid (AA) with the 23 miscoded AAs at the C-terminus. (E) Comparison results of quantitative RT-PCR analyses of the tshba and tshbb genes between the tshba mutant and its wild-type siblings at $5 \mathrm{dpf}$. (F) T4 immunofluorescence analyses at $5 \mathrm{dpf}$. The thyroid follicles are labeled in green for T4 with thyroxine immunofluorescence. Details of T4 immunofluorescent signals in the dotted white box are shown at high magnification. (G) Quantitative analyses of the T4 immunofluorescence signal at $5 \mathrm{dpf}$. Measurements were taken from wild-type zebrafish $(\mathrm{n}=10)$ and tshba mutants $(\mathrm{n}=9)$. (H) Quantitative RT-PCR analyses of TH synthesis-related genes, including the $t g$, slc5a5, and tpo gene in the tshba mutant and their wild-type siblings at $5 \mathrm{dpf}$. (I) Representative Western blotting of the TG protein from zebrafish at the $2 \mathrm{mpf}$ stage using anti-TG antibodies. (J) Quantification of the relative expression of TG protein of the Western blot analyses. Measurements were taken from wild-type zebrafish $(\mathrm{n}=5)$ and tshba mutants ( $\mathrm{n}=5)$. (K) Quantitative RT-PCR analyses of pituitary hormone genes, including cga, fshb, lhb, ghl, prl, pomca, smtla, and smtlb, in the tshba mutant and its wild-type sibling at $20 \mathrm{dpf}$. (L,M) Whole-body T4 levels (L) and T3 levels (M) in zebrafish at various stages. Measurements of THs were performed with three groups of wild-type zebrafish and three groups of tshba mutant zebrafish at 16, 20,25, and $60 \mathrm{dpf}$ stages. ${ }^{*} p<0.05 ;{ }^{* *} p<0.01$, ns: No significance.

\subsection{Growth Performance of the Tshba Mutant Zebrafish}

An apparent dwarfism phenotype in adult tshba mutant fish was recorded only after the $35 \mathrm{dpf}$ stage (Figure $2 \mathrm{~A})$.

A

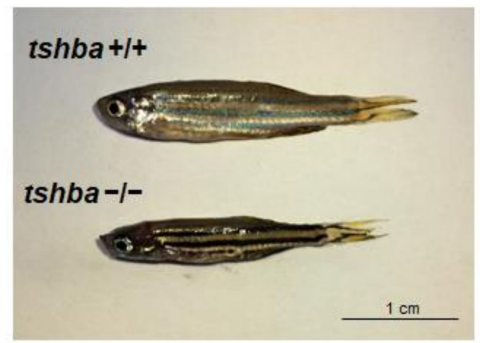

B

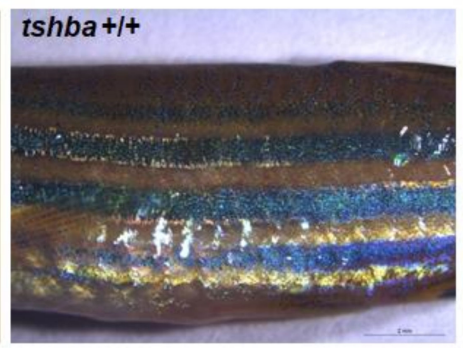

C

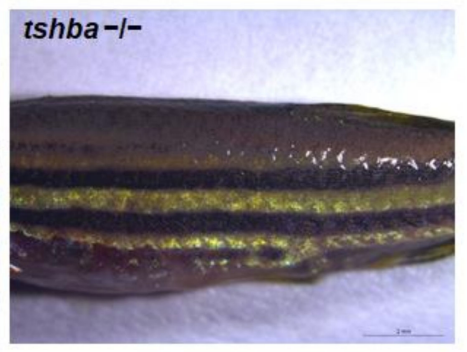

$\mathrm{D}$

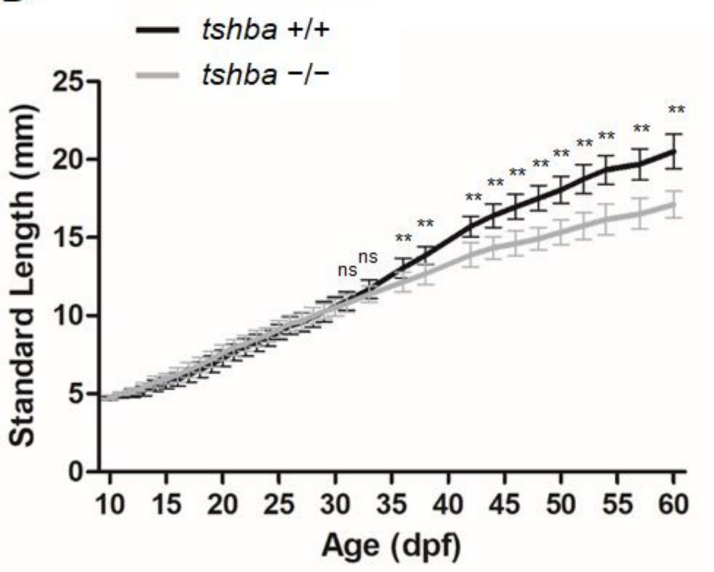

E

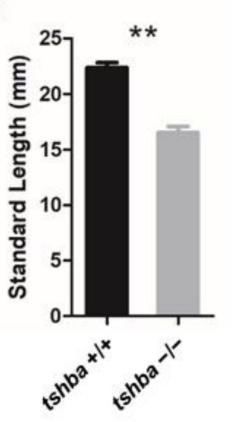

$\mathrm{F}$

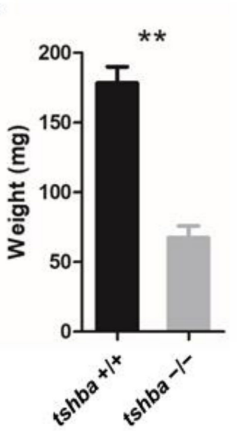

G

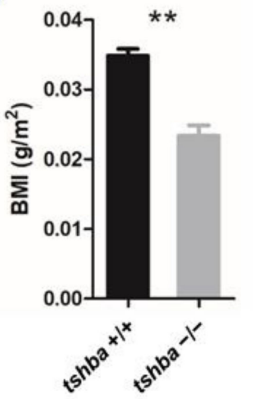

Figure 2. Somatic growth features of the tshba mutant fish and control wild-type siblings. (A) Wild-type control fish and tshba mutant zebrafish at 2 mpf. (B,C) Pigment pattern of wild-type control fish (B) and tshba mutant fish (C) at 2 mpf. (D) Curves of the somatic growth of wild-type control fish and tshba mutant fish. Means of standard length (SL) are presented as the growth curve. Measurements were performed with wild-type fish $(\mathrm{n}=10)$ and $t s h b a$ mutants $(\mathrm{n}=10)$. Significantly distinguishable differences beginning at $36 \mathrm{dpf}$. (E-G) SL (E), whole-body weight (F), and body mass index (G) of tshba mutant fish and their wild-type siblings at $2 \mathrm{mpf}$. Measurements were taken of wild-type fish $(\mathrm{n}=12)$ and $t s h b a$ mutant fish $(\mathrm{n}=10) .{ }^{* *} p<0.01$. 
In addition to this apparent phenotype, the altered pigment pattern has been observed in homozygous tshba mutants, the pigmentation of which was darker than that of their wildtype siblings at the two months post-fertilization (mpf) stage (Figure 2B,C). By measuring the body lengths and weights, it was found that the bodies of the tshba mutant fish were significantly shorter and less heavy than those of the control group, with a significant reduction in their body mass index (BMI) (Figure 2E-G).

To determine the exact stage when the growth phenotype of the tshba mutant fish can be distinguished from that of control fish, we measured the body length of wild-type and tshba mutant individuals from 10 to $60 \mathrm{dpf}$. The growth curves were drawn using the average SL data from 10 homozygous tshba mutants and 11 wild-type siblings. The results showed no significant differences between the sizes of tshba mutant fish and their wild-type siblings until $35 \mathrm{dpf}$ (Figure 2D). From the $35 \mathrm{dpf}$ onward, the size differences between the tshba mutants and the controls became increasingly apparent with age.

\subsection{Post-Embryonic Development of Tshba Mutant Zebrafish}

To further characterize tshba mutant fish during post-embryonic developmental progression, we thoroughly assessed the morphological features during the post-embryonic stages following the methods of previous studies [36,39]. We found that the period of aSB inflation and scale appearance (SP) were obviously delayed in tshba mutant fish compared to that in their wild-type counterparts (Figure 3A,B), while other stage-specific milestones described previously appeared normal in both tshba mutant and wild-type fish with no significant differences (Figure 3A,B).

Detailed observations on the relationships between the developmental stage and age revealed that tshba mutant fish took a longer time to reach the stage of proper aSB $(16.23 \pm 1.52 \mathrm{dpf}$ for wild-type vs. $20.71 \pm 2.34 \mathrm{dpf}$ for tshba mutant) and SP (28.92 $\pm 1.98 \mathrm{dpf}$ for wild-type vs. $55.70 \pm 4.42 \mathrm{dpf}$ for tshba mutant) formation compared to their wild-type siblings (Figure $3 \mathrm{~A}$ ). Correspondingly, the bodies of tshba mutant fish were significantly longer when they reached aSB $(6.24 \pm 0.16 \mathrm{~mm}$ for wild-type vs. $7.78 \pm 0.80 \mathrm{~mm}$ for $t$ shba mutant) and SP (10.31 $\pm 0.20 \mathrm{~mm}$ for wild-type vs. $16.33 \pm 1.04 \mathrm{~mm}$ for tshba mutant) formation stages, compared to those of their wild-type siblings (Figure 3B). In addition, while wild-type fish completed the anterior squamation process around the $30 \mathrm{dpf}$ stage, most tshba mutant fish did not develop their scales anterior to the dorsal fin by $60 \mathrm{dpf}$ (six of the ten mutant fish, data not shown).

We focused on the morphological features at 16 and $30 \mathrm{dpf}$ as these periods represent the average ages at which wild-type fish reach the aSB and SP formation stages, respectively. By $16 \mathrm{dpf}$, the wild-type larvae had an inflated aSB, while none of the tshba mutant larvae had an aSB (Figure 3C). By the $30 \mathrm{dpf}$ stage, a relatively larger aSB compared to the posterior swim chamber was seen in wild-type larvae, while in tshba mutant larvae, a relatively smaller inflated aSB was observed (Figure 3D). Among 15 tshba mutant larvae, one larva did not develop an inflated aSB at $30 \mathrm{dpf}$ (data not shown). In wild-type fish at $30 \mathrm{dpf}$, scales were apparent anterior to the dorsal fin, as evidenced by ridges (Figure 3E). In contrast, none of the tshba mutant fish of the same age developed scales (Figure 3F). In addition, when only small remnants of the pelvic fin fold were present ventrally in wildtype fish (Figure 3E,e2), the pelvic fin fold of tshba mutant fish was much more apparent and remained to be resorbed (Figure 3F,f2).

\subsection{Rescue Effects of the Supplemental Exogenous T3 Treatments on Tshba Mutants}

To further correlate the defective aSB inflation and scale development with the thyroid dyshormonogenesis observed in tshba mutant fish, a rescue experiment with supplemental exogenous T3 treatment was performed. We treated the F2 offspring of tshba-heterozygote mutants with T3 dissolved in the aquarium water starting at $12 \mathrm{dpf}$. At $18 \mathrm{dpf}$, both T3and DMSO-treated wild-type larvae developed normal inflated aSBs (Figure 4A,B). 

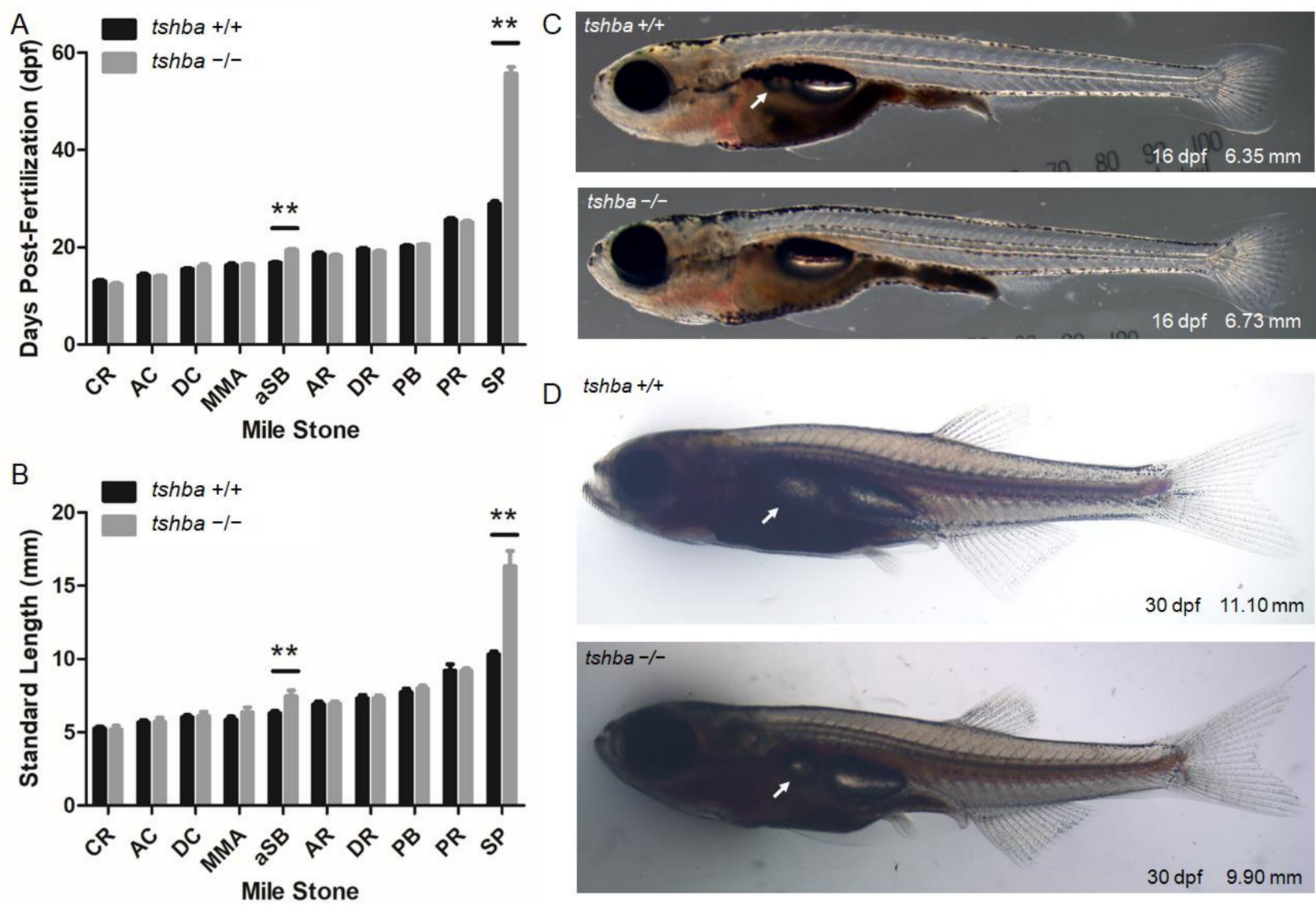

$\mathrm{D}$
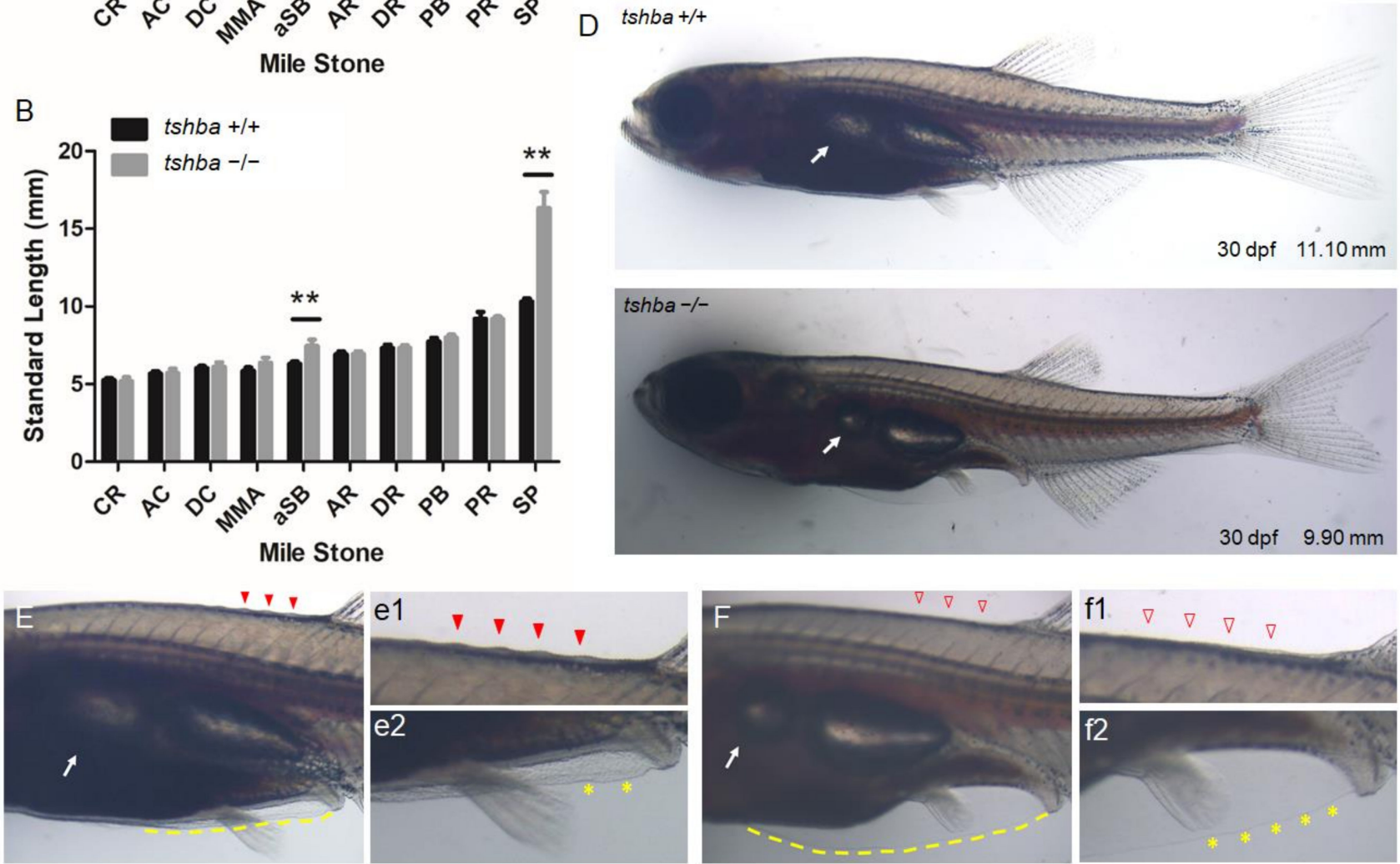

Figure 3. Comparative morphological analyses between wild-type fish and tshba mutant fish prior to the juvenile stage. (A) Comparative morphological features and their relationships with age of fish between tshba mutant zebrafish and their wild-type siblings. (B) Comparative morphological features observed and their relationships with fish size between tshba mutant zebrafish and wild-type siblings. The x-axes show developmental milestones describing early larval stages (left) toward late larval stages (right). Measurements were taken of wild-type fish $(\mathrm{n}=11)$ and $t$ shba mutants $(\mathrm{n}=10)$. (C) Morphological features of wild-type and tshba mutants at $16 \mathrm{dpf}$. Arrows indicate the appearance of inflated anterior swim bladders. (D) Morphological features of wild-type and tshba mutants at $30 \mathrm{dpf}$. Arrows indicate the appearance of inflated aSBs. (E) Higher magnification views of wild-type fish (30 dpf) showing an inflated aSB (arrows), anterior squamation (SA; details in (e1), red arrowhead), minor fin fold (dotted yellow line, details in (e2) labelled with yellow asterisks), vent, and anal fin. (F) Higher magnification views of tshba mutant fish (30 dpf) showing a smaller inflated aSB (arrows), SA (details in (f1), red arrowhead), minor fin fold (dotted yellow line, details in (f2) labeled with yellow asterisks), vent, and anal fin. Stage abbreviations: CR, caudal fin ray appearance; AC, anal fin condensation; DC, dorsal fin condensation; MMA, metamorphic melanophore appearance; aSB, inflation of anterior swim bladder lobe; AR, anal fin ray appearance; $\mathrm{DR}$, dorsal fin ray appearance; $\mathrm{PB}$, pelvic fin bud appearance; $\mathrm{PR}$, pelvic fin ray appearance; $\mathrm{SP}$, posterior squamation; SA, anterior squamation.** $p<0.01$. 

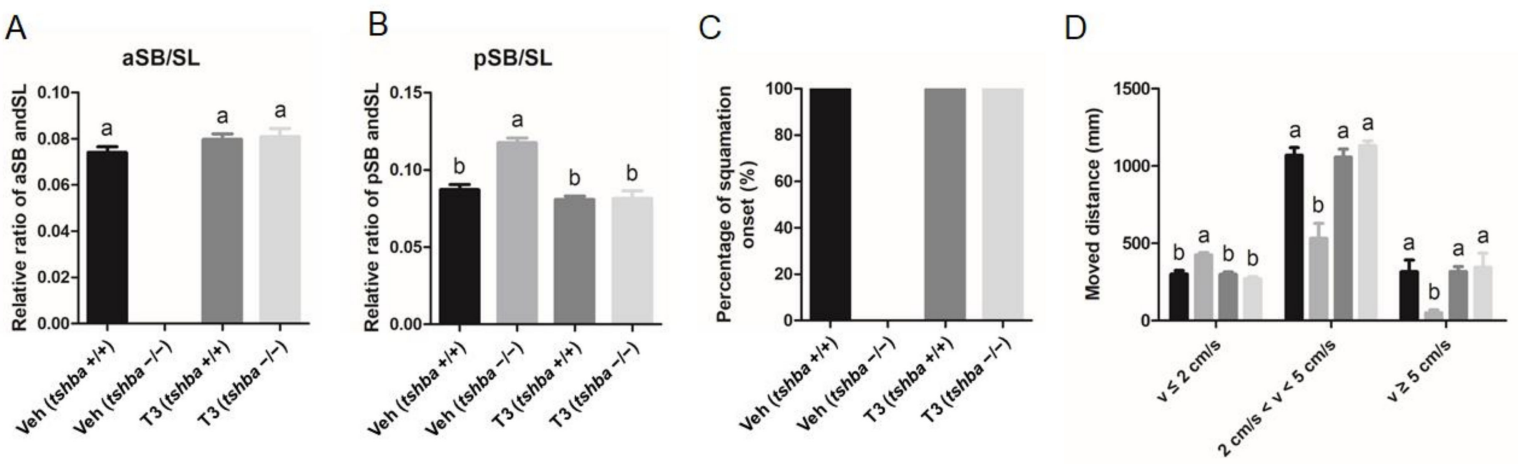

Veh $($ tshba +/+) $9.600 \mathrm{~mm}$

Veh (tshba -l-)

T3 (tshba +/+) $9.704 \mathrm{~mm}$

T3 (tshba -/-) $9.684 \mathrm{~mm}$
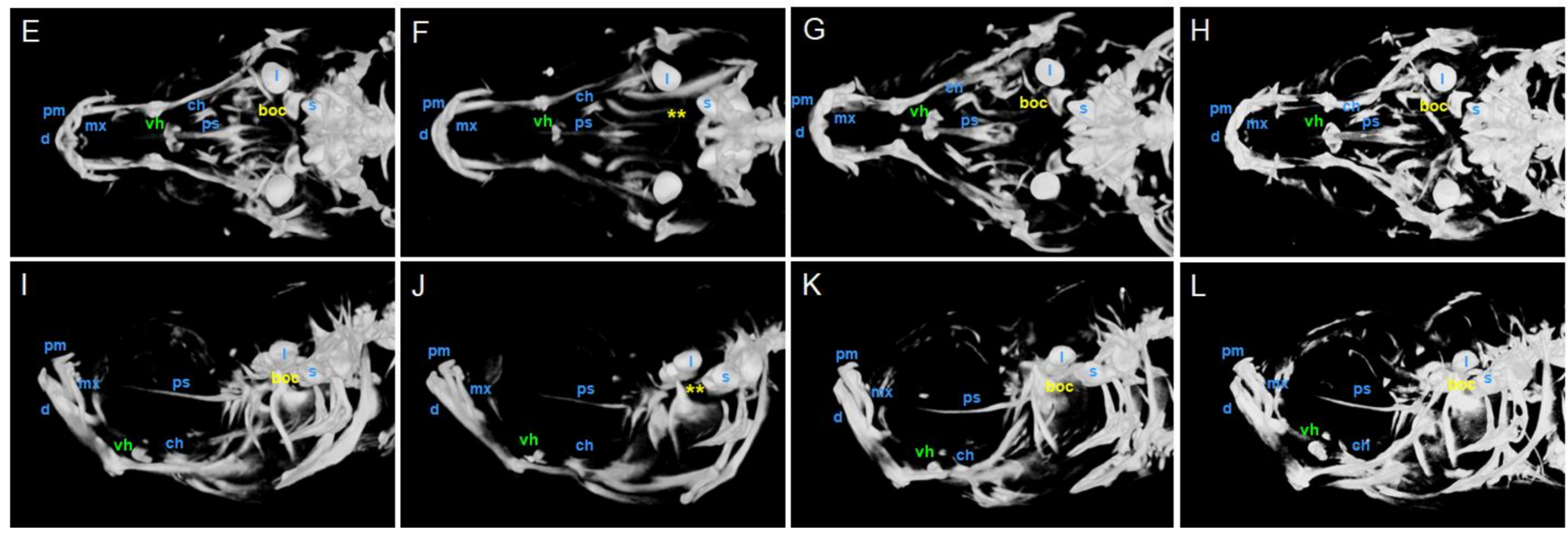

Figure 4. Larval-to-juvenile transition defects rescued by supplemental T3 treatments in tshba mutant zebrafish. (A) Relative ratios of the relative length of the aSB to the standard length (SL) of the zebrafish body at 20 dpf. (B) Relative ratios of the relative length of the posterior swim bladder (pSB) to the SL of zebrafish body at $20 \mathrm{dpf}$. (C) Percent onset of squamation in zebrafish at $32 \mathrm{dpf}$. (D) The locomotive activity of zebrafish at $30 \mathrm{dpf}$. The x-axes show the movement velocity. The swimming ability of zebrafish is shown by the moving distance with low velocity $(\mathrm{v} \leq 2 \mathrm{~cm} / \mathrm{s})$, medium velocity $(2 \mathrm{~cm} / \mathrm{s}<\mathrm{v}<5 \mathrm{~cm} / \mathrm{s})$, and high velocity $(\mathrm{v} \geq 5 \mathrm{~cm} / \mathrm{s})$. (E-H) Micro-CT scan of the craniofacial skeleton in zebrafish at $30 \mathrm{dpf}$. Dorsal view. (I-L) Micro-CT scan of the craniofacial skeleton in zebrafish at $30 \mathrm{dpf}$. Lateral view. Images not to scale. The SL of each zebrafish is presented above the panels. The basioccipital bones are labeled in yellow. The ventral hypohyals are labeled in green. Yellow asterisks indicate the bony process on the basioccipital, which did not appear in control tshba mutant zebrafish. Abbreviations: boc, basioccipital; d, dentary; l, lapillus; mx, maxilla; pm, premaxilla; ps, parasphenoid; vh, ventral hypohyals; s, sagitta. $a-b$, different superscripts in the same column indicate significant differences $(p<0.05)$.

aSB inflation was not observed in DMSO-treated tshba mutant larvae, and this resulted in a bigger posterior swim bladder; however, all of the T3-treated tshba mutant fish developed normally inflated aSBs.

At $32 \mathrm{dpf}$, scales were observed in wild-type fish but not in tshba mutant fish in the DMSO-treated group. However, the tshba mutant fish developed scales as their wild-type siblings did after T3 treatment at $32 \mathrm{dpf}$ (Figure 4C). As a result, the defective phenotypes regarding aSB and SP formation during the post-embryonic development in tshba mutant zebrafish were effectively rescued by T3 treatment.

By $30 \mathrm{dpf}$, the swimming ability of tshba mutant fish was affected, compared to that of their control wild-type siblings (Figure 4D). In comparison with wild-type zebrafish, the distance that $t$ shba mutant zebrafish moved with high $(\mathrm{v} \geq 5 \mathrm{~cm} / \mathrm{s})$ and medium velocity $(2 \mathrm{~cm} / \mathrm{s}<\mathrm{v}<5 \mathrm{~cm} / \mathrm{s})$ decreased significantly, while the distance moved with low velocity $(\mathrm{v} \leq 2 \mathrm{~cm} / \mathrm{s})$ increased significantly. T3 treatment rescued the locomotive defect in tshba mutant zebrafish. After T3 treatment $(2.5 \mu \mathrm{g} / \mathrm{L})$, no significant differences were observed in the distance covered at three velocity levels between $t s h b a$ mutant zebrafish 
and their wild-type siblings. However, without T3 treatment, the moving activity of tshba mutant zebrafish was significantly different from that of the wild-type zebrafish in the control group. Thus, our results indicated that $t$ shba mutant fish could have their normal swimming ability restored through external T3 supplementation.

The craniofacial skeleton of zebrafish at $30 \mathrm{dpf}$ was examined under X-ray with microCT visualization. The cranial ossification was largely completed in wild-type zebrafish by $30 \mathrm{dpf}$ (Figure 4E,I). However, general retarded craniofacial ossifications were observed in tshba mutant fish relative to the control wild-type fish (Figure $4 \mathrm{~F}, \mathrm{~J}$ ). The appearance of basioccipital bones was observed in wild-type fish but not in tshba mutant fish at $30 \mathrm{dpf}$, while the ventral hypohyal was smaller in tshba mutant fish compared with that of the control fish (Figure 4E,F,I,J). After T3 supplementation, the skulls were mostly ossified by $30 \mathrm{dpf}$ in both wild-type and tshba mutant zebrafish (Figure $4 \mathrm{G}, \mathrm{H}, \mathrm{K}, \mathrm{L}$ ), and the basioccipital bones were observed in the cranial region in tshba mutant zebrafish.

\subsection{Reproductive Defects Observed in Tshba Mutant Zebrafish}

Initially, no progeny was obtained from the mating between homozygous tshba mutant parents. To further address the reasons for reproductive performance defects in tshba mutant zebrafish, histological analyses of gonadal tissues in the tshba mutants were conducted. Surprisingly, the histological structures of the gonads were not affected in either male or female tshba mutant zebrafish, when compared with the wild-type zebrafish gonads. Similar patterns of oocytes were observed in both tshba mutant ovaries and those of wild-type control fish (Figure 5A,B), and similar histological features of the male germ cells were observed in both tshba mutant and wild-type testes (Figure 5C,D). Thus, the maturation of gonads in the tshba mutants was not affected.

To further address the effects of tshba mutation on reproduction performance, we investigated the secondary sex characteristics (SSCs) of the tshba mutant. A decrease in vent size was observed anterior to the anal fin in tshba mutant female adult zebrafish compared to that in wild-type female zebrafish (Figure 5F,I). In addition, tshba mutant male adult fish completely lost their breeding tubercles on the pectoral fin, while control wild-type zebrafish exhibited clear breeding tubercles (Figure 5M,P). These results demonstrate the defective development of SSCs, caused by impaired TSH signaling in zebrafish.

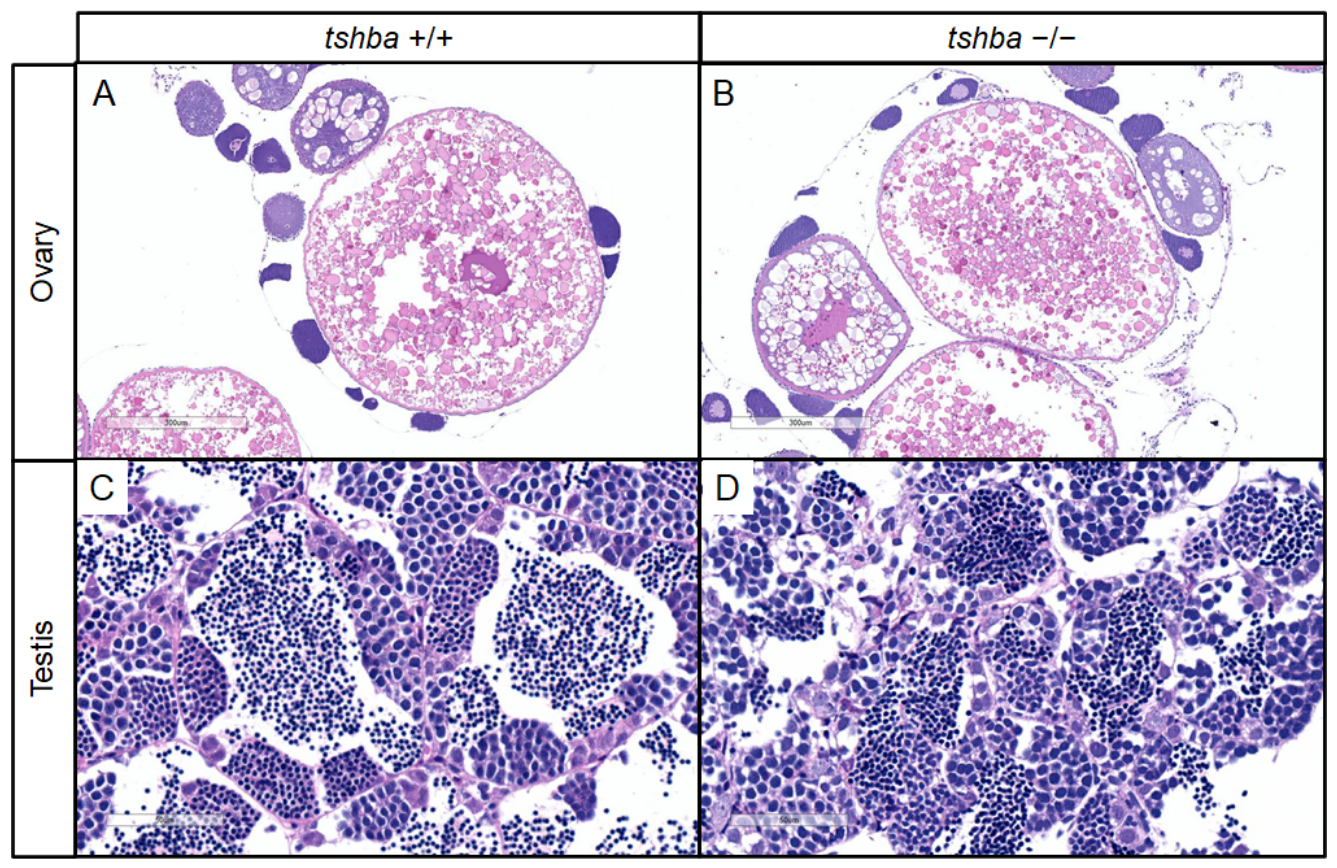

Figure 5. Cont. 


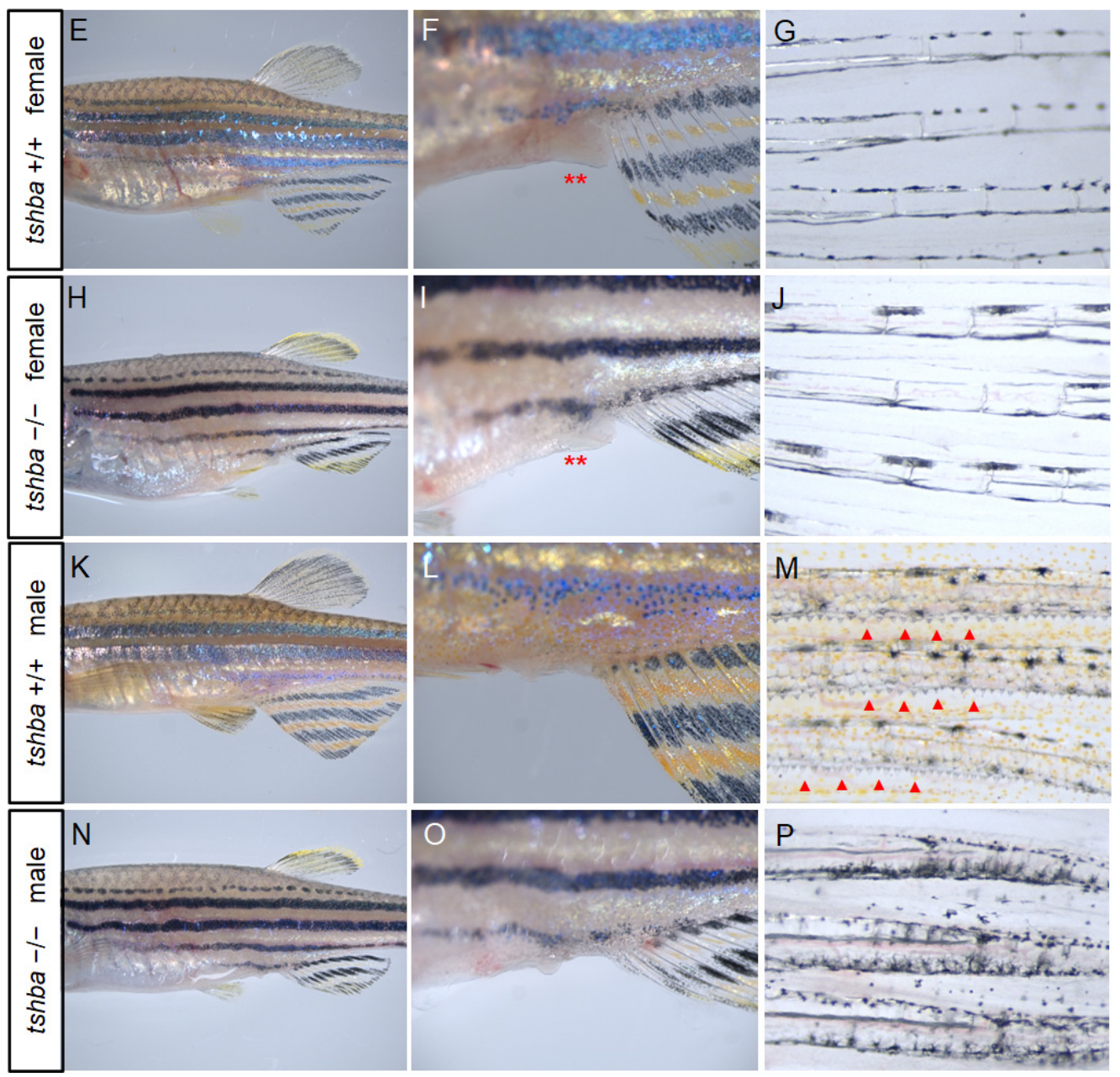

Figure 5. Changes in secondary sex characteristics in tshba mutant zebrafish. (A,B) Representative histological sections of ovaries from wild-type zebrafish at $4 \mathrm{mpf}(\mathrm{A})$ and from tshba mutant zebrafish at $8 \mathrm{mpf}(\mathbf{B})$ by H\&E staining. (C,D) Representative histological sections of testes from wild-type zebrafish at $4 \mathrm{mpf}(\mathbf{C})$ and from tshba mutant zebrafish at $8 \mathrm{mpf}(\mathbf{D})$ by H\&E staining. $(\mathbf{E}, \mathbf{H}, \mathbf{K}, \mathbf{N})$ Gross morphology of wild-type female fish at $4 \mathrm{mpf}(\mathbf{E})$, tshba mutant female fish at $8 \mathrm{mpf}(\mathbf{H})$, wild-type male fish at $4 \mathrm{mpf}(\mathbf{K})$, and tshba mutant male fish at $8 \mathrm{mpf}(\mathbf{N})$. (F,I) Representative female vent in wild-type (F) and tshba mutant (I) fish. Red asterisks indicate the vent anterior to the anal fin. $(\mathbf{L}, \mathbf{O})$ Representative male vent in the wild-type (L) and tshba mutant (O) fish. (G,J,M,P) Pectoral fins of wild-type female fish (G), tshba mutant female fish (J), wild-type male fish (M), and tshba mutant male fish (P) are shown. Representative breeding tubercles (BTs) were seen in wild-type male fish (M). No BTs were seen in tshba mutant male fish (L). Red arrowheads indicate the BTs on the pectoral fins.

\subsection{Generation of tg Mutant Zebrafish}

The CRISPR system was used to generate $t g$ mutant zebrafish. Based on the zebrafish tg mRNA sequence (NM_001329865.1) from GenBank, the zebrafish tg gene was identified as a single copy gene on Chromosome 16. The tg locus (LR812078.1) contains an $8202 \mathrm{bp}$ coding sequence divided into 46 exons spanning over $64 \mathrm{~kb}$, with 2733 predicted AAs. The targeting site was selected at the fourth exon of the $t g$ gene. Two independent mutant lines, one with a 4 bp deletion ( $t g-4$ line) and another with an 11 bp deletion ( $t g-11$ line) were generated (Figure 6A). 

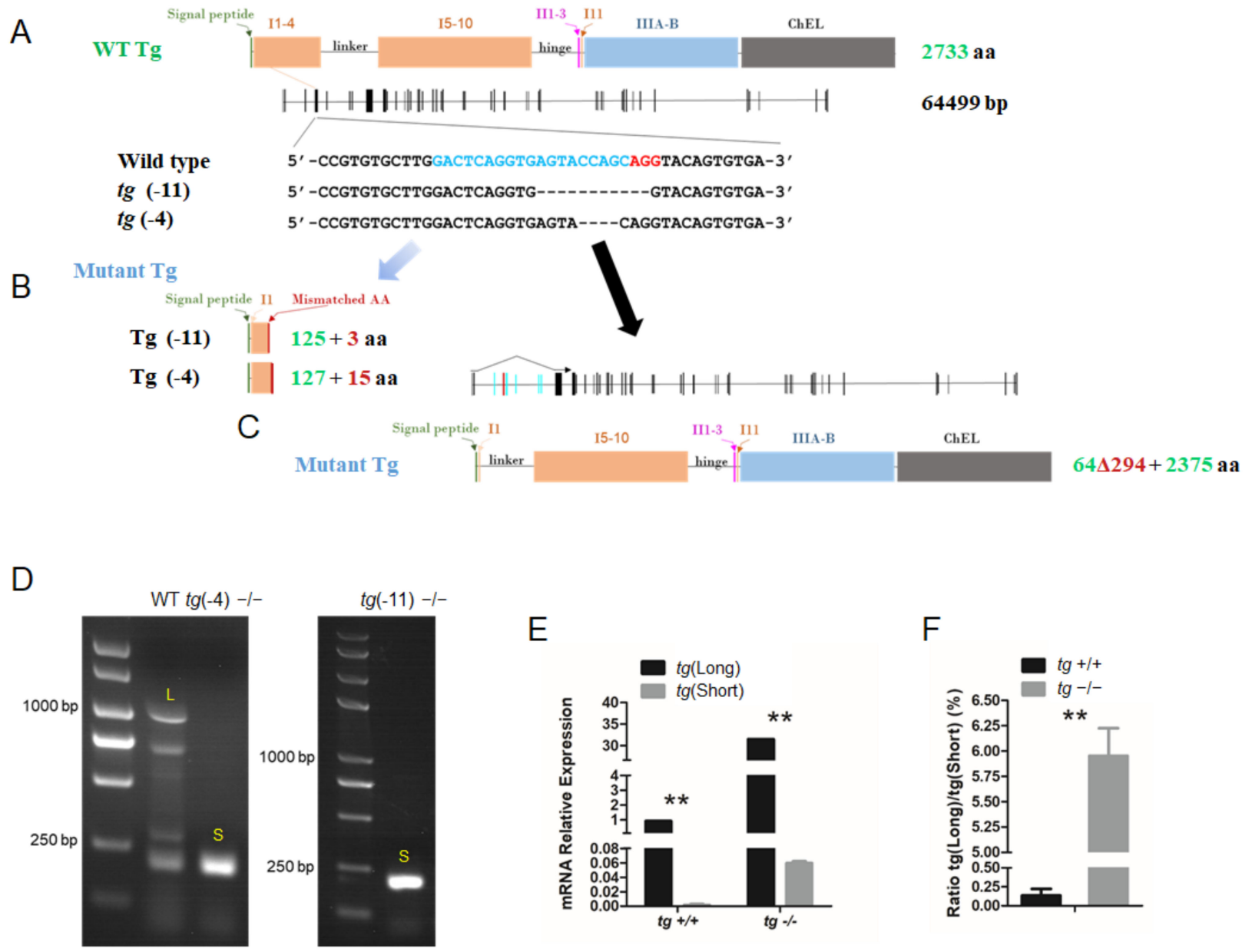

E

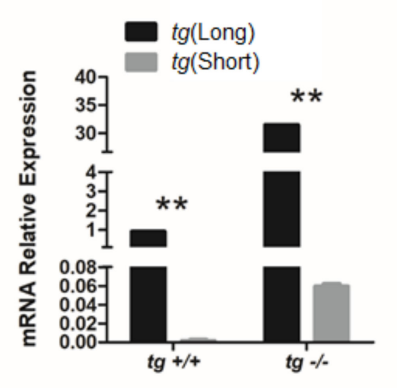

$\mathrm{H}$

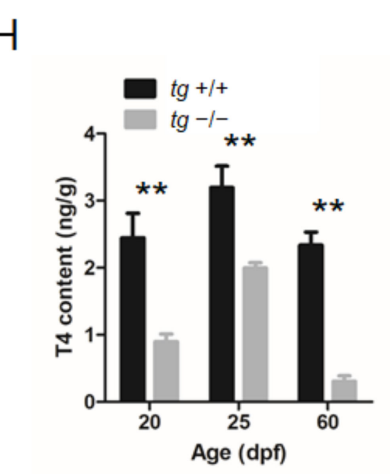

F

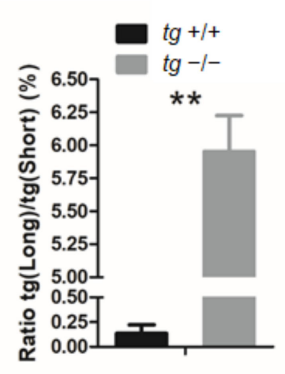

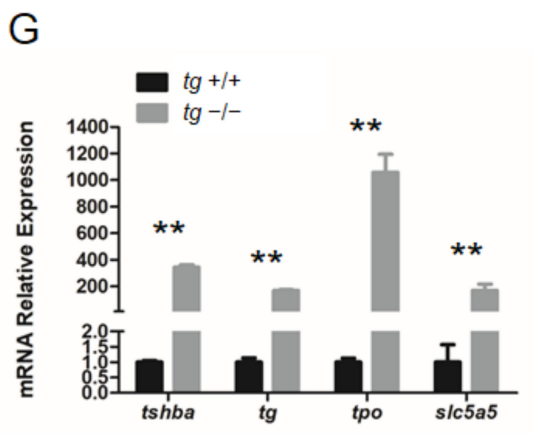

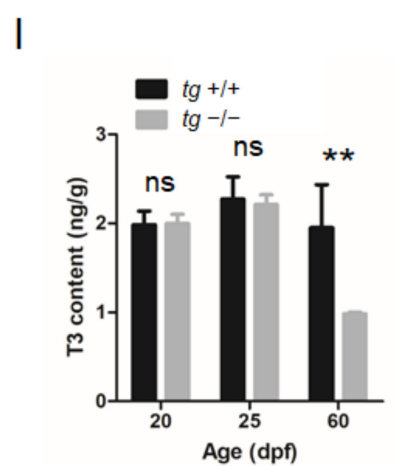

Figure 6. Generation of $\operatorname{tg}$ mutant zebrafish. (A) Schematic illustration representing the zebrafish Tg protein, the genomic structure of $t g$, and the CRISPR target site on exon 4 . Sequencing of the $t g$ CRISPR target site in wild type, $t g(-4)$ mutant, and $\operatorname{tg}(-11)$ mutant zebrafish lines are shown in the lower panel. (B) The predicted truncated Tg proteins resulting from premature translational terminations are shown. (C) Proteins resulting from the alternative short transcript are shown. (D) The alternative short transcripts can be amplified in wild-type fish and $t g$ mutants. The long transcripts were indicated by the letter L. The short transcripts were indicated by the letter S. (E) Quantification of the expression levels of the $t g$ full-length transcript and short transcript in $t g$ mutants and their wild-type siblings. (F) Ratio of the tg full-length transcript and short transcript expression in $t g$ mutants and their wild-type siblings. (G) Quantitative RT-PCR analyses of $t s h b a, t g$, $t p o$, and slc5a5 expression levels in $t g$ mutants and their wild-type siblings at $5 \mathrm{dpf}$. (H) Whole-body T4 contents of $t g$ mutants and their wild-type siblings at the 20, 25, and $60 \mathrm{dpf}$ stages. (I) Whole-body T3 contents of $t g$ mutants and their wild-type siblings at the 20,25 , and $60 \mathrm{dpf}$ stages. ${ }^{* *} p<0.01$, ns: No significance. 
Unless otherwise noted, the $t g-4$ mutant zebrafish line was used for the experiments. These mutations in the $\mathrm{tg}$ locus resulted in a reading frame shift and premature termination (Figure 6B). However, a short form of the alternative splicing $t g$ transcript lacking exon 3-8 was detected in the $\operatorname{tg}$ mutant zebrafish (Figure 6C,D). Both the native full-length $\mathrm{tg}$ transcript and this alternative splicing transcript form can actually be amplified from wild-type zebrafish, but dramatically elevated levels of the short alternative transcript form were observed in the $\mathrm{tg}$ mutants (Figure 6E,F). These alternatively spliced isoforms retained many important $\mathrm{Tg}$ functional domains that may still perform some of the core functions of Tg. To assess the functional consequence of the $t g$ mutations in zebrafish, the expression changes of genes related to thyroid function were assayed by qRT-PCR in $t g$ mutant fish at $5 \mathrm{dpf}$. A general trend towards upregulation was observed, with a considerable increase of $t s h b a, t g, t p o$, and slc5a5 in the tg mutants (Figure 6G). Moreover, body T4 levels measured at 20,25, and $60 \mathrm{dpf}$ were significantly reduced in $\mathrm{tg}$ mutant zebrafish compared to those of wild-type zebrafish at same stages respectively (Figure $6 \mathrm{H}$ ). T3 levels were significantly reduced at $60 \mathrm{dpf}$ in $\mathrm{tg}$ mutant zebrafish, while no significant difference in T3 levels at 20 and $25 \mathrm{dpf}$ was found between $\mathrm{tg}$ mutants and wild-type zebrafish (Figure 6I).

\subsection{Generation of slc16a2 Mutant Zebrafish}

The zebrafish slc16a2 gene (NW_003335266.1) was also targeted using the CRISPR system. The targeting site was chosen in the first exon of the slc16a2 gene. Two independent mutant lines, one with a $10 \mathrm{bp}$ deletion (slc16a2-10 line) and another with a 28 bp deletion (slc16a2-28 line) were generated (Figure 7A).

Unless otherwise noted, the slc16a2-28 mutant zebrafish line was used for experiments. The mutations in slc16a2 resulted in the reading frame shift and premature terminations (Figure 7B). In these mutant fish at the $5 \mathrm{dpf}$ stage, the expression levels of $t s h b a, t g, t p o$, and slc5a5 were significantly upregulated in slc16a2 mutant zebrafish (Figure 7C). One remarkable exception was the dramatic reduction in three thyroid hormone transporters (slc16a2, slc16a10, and slco1c1) in slc16a2 mutant zebrafish (Figure 7D). In terms of the TH production in slc16a2 mutant fish, the T4 levels of slc16a2 mutant zebrafish significantly increased at $60 \mathrm{dpf}$ compared to those of wild-type zebrafish, while the T4 levels at 20 and $25 \mathrm{dpf}$ were not significantly affected (Figure 7E). In terms of T3 production, no significant change was observed at 20,25, and $60 \mathrm{dpf}$ in slc16a2 mutant zebrafish (Figure 7F).

\subsection{General Phenotype Observed in tg and slc16a2 Mutant Zebrafish}

Since significant alterations in certain TH levels of $t g$ and slc16a2 mutant zebrafish were observed at $60 \mathrm{dpf}$ (Figure 6H,I and Figure 7E,F), the morphological features of the mutant fish were subsequently investigated. Both $\mathrm{tg}$ and slc16a2 mutant zebrafish exhibited normal shapes and pigmentation patterns as those of wild-type zebrafish (Figure 8A,B).

Bodyweight and SL of zebrafish at $60 \mathrm{dpf}$ were measured. The weight and length of the tg mutant fish were both significantly lower than those of wild-type fish; correspondingly, the BMI was reduced in $t g$ mutant zebrafish (Figure $8 \mathrm{C}-\mathrm{E}$ ). Unlike the $t g$ mutants, the body weight, body length, and BMI of slc16a2 mutant fish were not significantly affected compared to those of their wild-type siblings (Figure 8F-H). Notably, no apparent goiter was found in tshba mutant zebrafish (Supplementary Figure S2), while typical goiters of a large red protrusive mass were observed under the jaw and anterior to the heart in $t g$ and slc16a2 mutant zebrafish at $3 \mathrm{mpf}$ (Figure 9A-E), and the mass in tg mutant zebrafish was larger than that in slc16a2 mutant zebrafish. These results suggest that mutations of $t g$ and slc16a2 cause goiter in zebrafish.

Due to defects of inflation of aSB and the onset of scales in tshba mutant fish, we subsequently investigated the development of aSB and scales in $\mathrm{tg}$ and slc16a2 mutant fish. At 20 and $32 \mathrm{dpf}$, no evident defects of the key features involved in LTJT were observed in either $\operatorname{tg}$ or slc16a2 mutant fish (Supplementary Figure S3). These results indicated that the LTJT was not affected in either $t g$ or slc16a2 mutant zebrafish. 
A

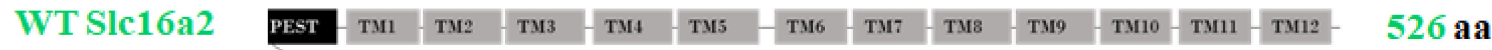

Wild type

slc16a2 (-28)

slc16a2 (-10)
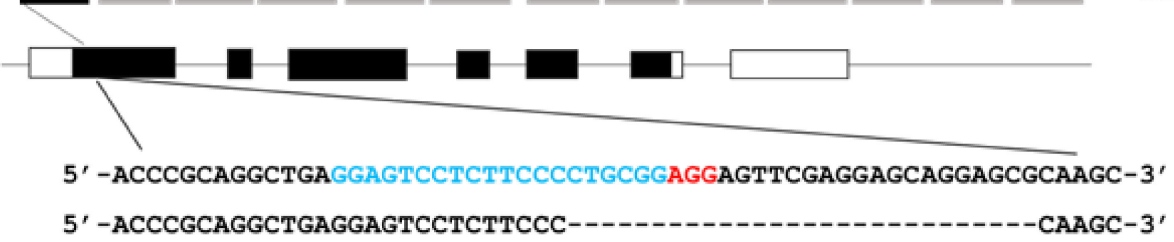

$5^{\prime}$-ACCCGCAGGCTGAGGAGTCCTCTTCC-T-------GTTCGAGGAGCAGGAGCGCAAGC-3'

B Mutant Slc16a2

$\begin{array}{lll}\text { Slc16a2 (-28) } & \longmapsto & 27+66 \text { aa } \\ \text { Slc16a2(-10) } & \longmapsto & 26+73 \text { aa }\end{array}$

93 aa

99 aа
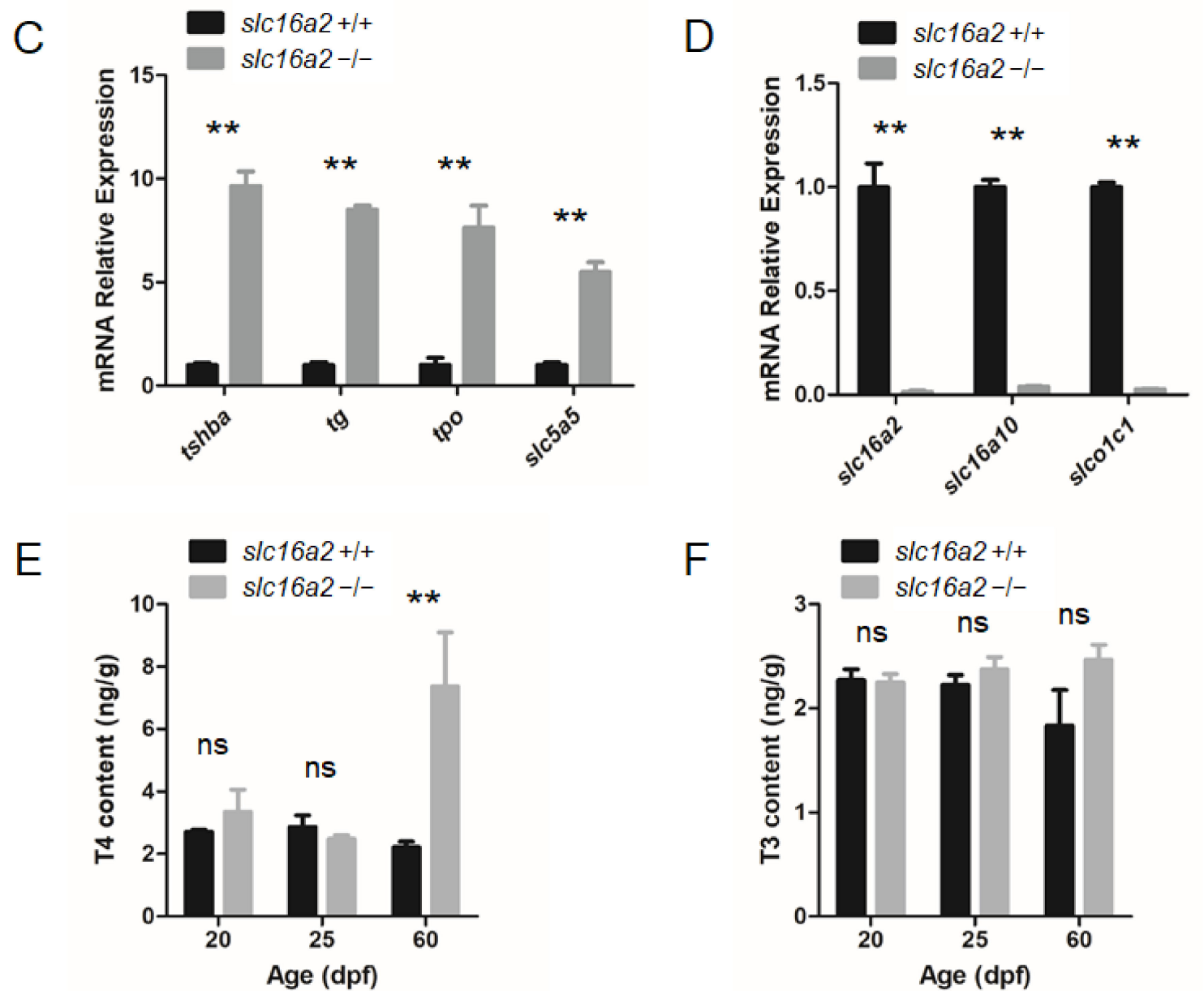

Figure 7. Generation of the slc16a2 mutant zebrafish. (A) Schematic illustration representing the zebrafish Slc16a2 protein (upper panel) and slc16a2 locus with the CRISPR target site on exon 1 (middle panel). Sequencing of the slc16a2 target CRISPR site in wild type, slc16a2 (-28) mutant, and slc16a2 (-10) mutant zebrafish lines are shown in the lower panel. (B) The predicted truncated Slc16a2 proteins resulting from premature translational termination are shown. (C) Quantitative RT-PCR analyses of $t s h b a, t g, t p o$, and slc5a5 expression in slc16a2 mutants and their wild-type siblings at 5 dpf. (D) Quantitative RT-PCR analyses of slc16a2, slc16a10, and slco1c1 expressions in slc16a2 mutants and their wild-type siblings at 5 dpf. (E) Whole-body T4 contents of slc16a2 mutants and their wild-type siblings at 20, 25, and $60 \mathrm{dpf}$. (F) Whole-body T3 contents of slc16a2 mutants and their wild-type siblings at 20, 25, and $60 \mathrm{dpf}$. ${ }^{* *} p<0.01$, ns: No significance. 

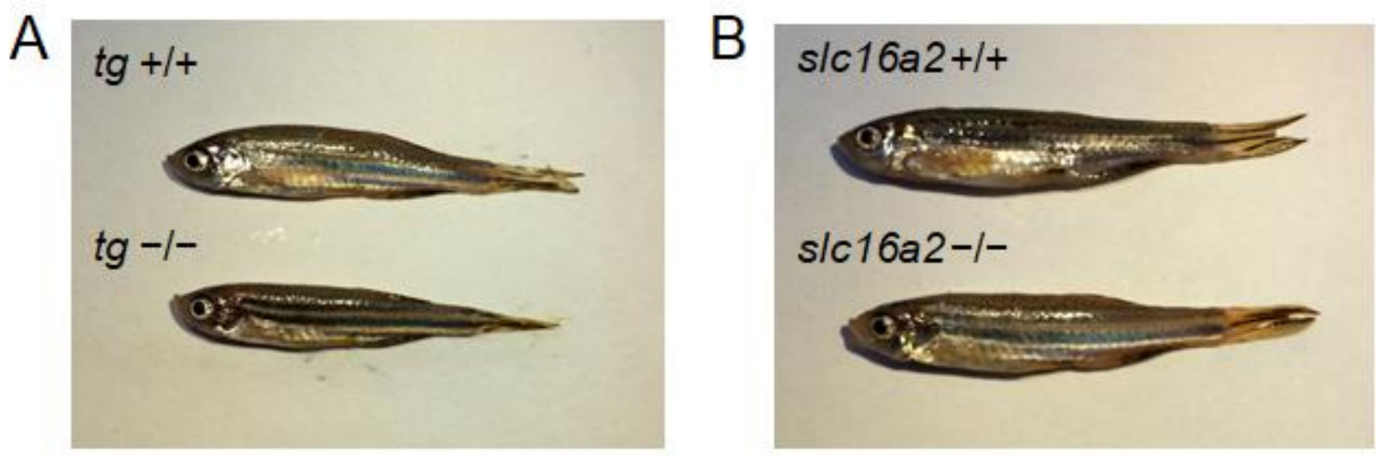

C

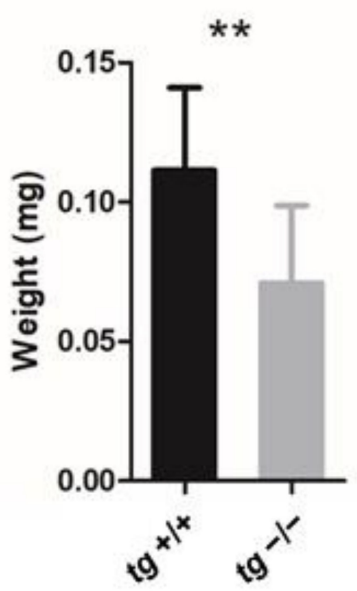

$\mathrm{F}$

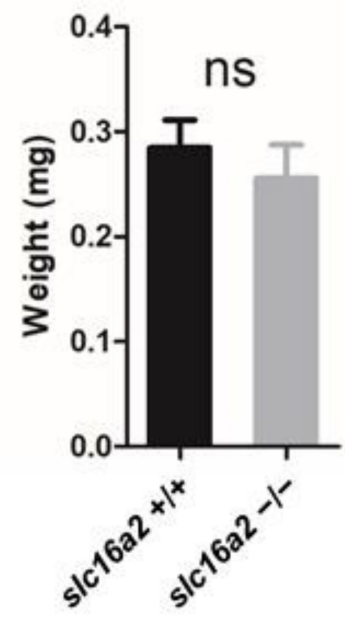

D

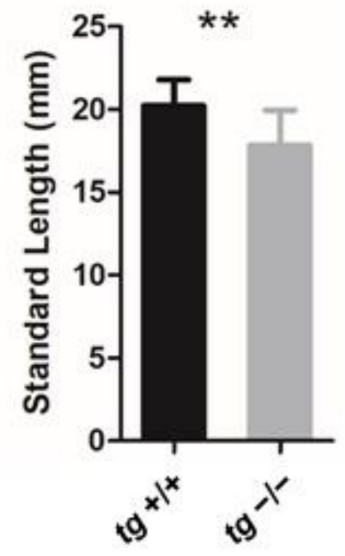

G

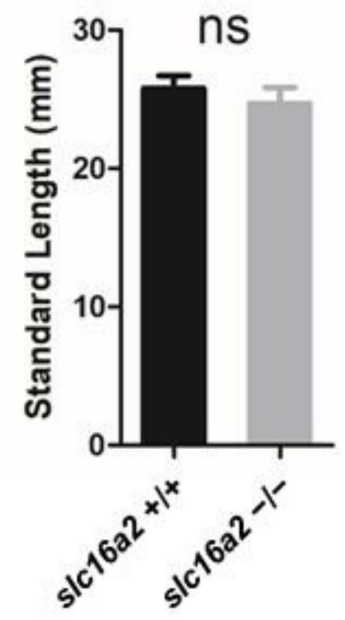

E

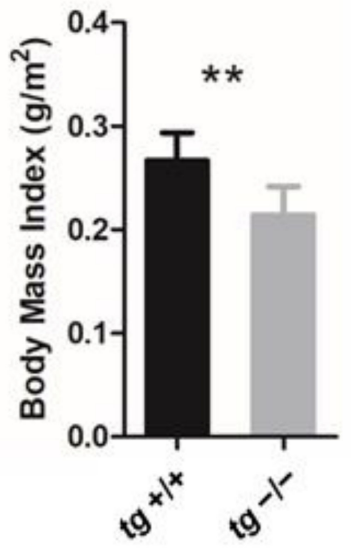

$\mathrm{H}$

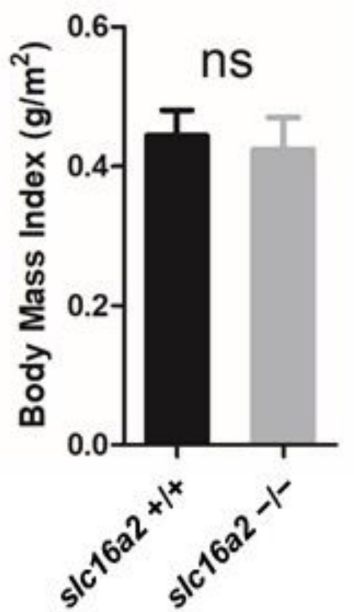

Figure 8. Somatic growth in tg or slc16a2 mutant zebrafish. (A) Control wild-type zebrafish and tg mutant zebrafish at 2 mpf. (B) Control wild-type zebrafish and slc16a2 mutant zebrafish at $2 \mathrm{mpf}$. (C-E) Body weight (C), standard length (SL) (D), and body mass index (BMI) (F) of $t g$ mutants and their wild-type siblings at 2 mpf. Measurements were taken from wild-type fish $(\mathrm{n}=12)$ and $\operatorname{tg}$ mutant fish $(\mathrm{n}=13)$. $(\mathbf{F}-\mathbf{H})$ Body weight $(\mathbf{F})$, SL $(\mathbf{G})$, and BMI $(\mathbf{H})$ of slc16a2 mutants and their wild-type siblings at 2 mpf. Measurements were taken from wild-type fish $(n=6)$ and slc16a2 mutant fish $(n=8){ }^{* *} p<0.01$, ns: No significance. 

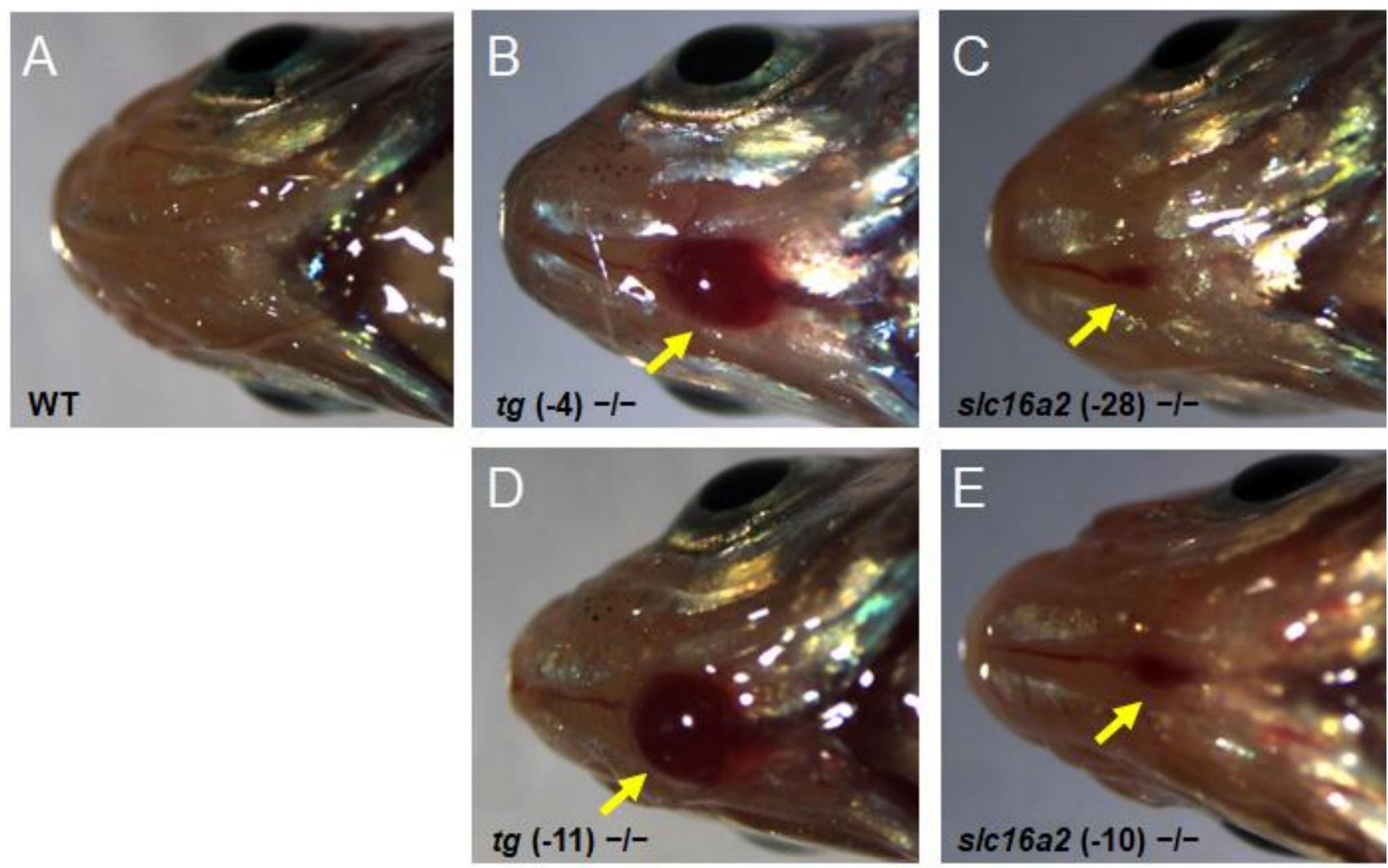

Figure 9. Goiter seen in $\mathrm{tg}$ mutant and slc16a2 mutant zebrafish. (A-E) Representative macroscopical pictures of the head region of wild-type zebrafish (A), $\operatorname{tg}(-4)$ zebrafish (B), $\operatorname{tg}(-11)$ mutant zebrafish (C), slc16a2 (-10) mutant zebrafish (D), and slc16a2 (-28) mutant zebrafish (E) at $3 \mathrm{mpf}$. The red mass of the thyroid is indicated by the yellow arrows.

\subsection{Divergent Effects of Reproduction in Various Zebrafish Hypothyroidism Models}

No evident defective reproductive activities were identified in homozygous $t g$ or slc16a2 mutants, while no progenies were produced from tshba mutants. To further analyze the effects of various hypothyroidisms on reproductive performance, the mating behaviors of wild-type fish (4 and $8 \mathrm{mpf})$, tshba mutants ( $8 \mathrm{mpf})$, $t g$ mutants (4 mpf), and slc16a2 mutants (4 mpf) were examined. No significant differences were found between the frequency and duration of intimate contact $(<2 \mathrm{~cm})$ among wild-type fish at $4 \mathrm{mpf}$ and wild-type fish at $8 \mathrm{mpf}$ in both sexes (Figure 10A-D).

There was significantly reduced frequency and duration of intimate contact when mating was set up between tshba mutant males with wild-type females (4 mpf). However, no such phenomenon was observed when the mating involved $t g$ or slc16a2 mutant male zebrafish (Figure 10A,B). Consistently, the tshba mutant female fish exhibited significantly decreased intimacy with wild-type male fish $(4 \mathrm{mpf})$, while the mating behavior of $t g$ and slc16a2 mutant female zebrafish with wild-type males (4 mpf) was not significantly affected (Figure 10C,D). Hypotestosterone levels may be caused by a specific form of hypothyroidism in mammals [40]. As the testosterone level was generally considered to be associated with reproductive activities, the testosterone levels in the gonads of wild-type fish (4 and $8 \mathrm{mpf})$, tshba mutants ( $8 \mathrm{mpf})$, tg mutants ( $4 \mathrm{mpf})$, and slc16a2 mutants (4 mpf) were measured. The gonadal testosterone levels among wild-type fish at $4 \mathrm{mpf}$ and wildtype fish at $8 \mathrm{mpf}$ showed no significant differences in either sex. Moreover, no significant changes in testosterone levels of the testes or ovaries were found in $t s h b a$, $t g$, or slc16a2 mutant zebrafish compared to those of the control wild-type fish (4 mpf) (Supplementary Figure S4). Therefore, this indicates that the reproductive defects observed in tshba mutants are not associated with the gonadal levels of testosterone. 
A
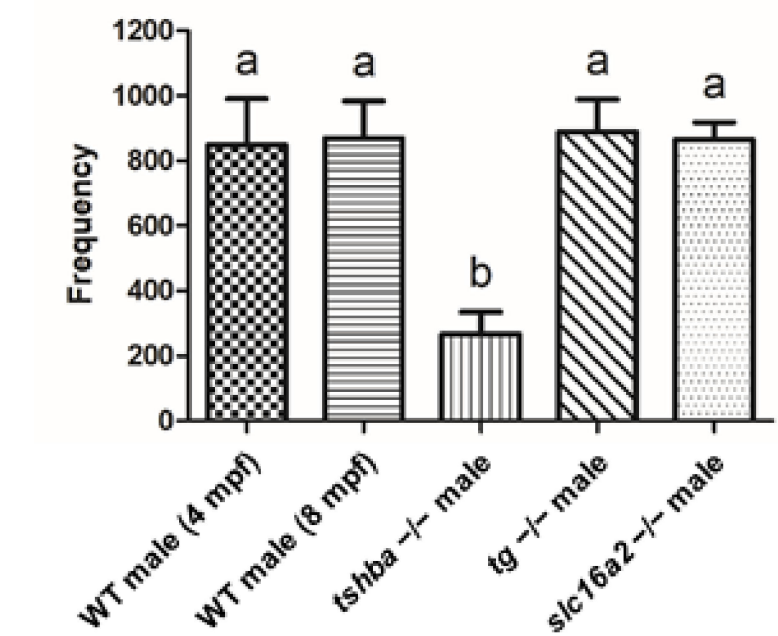

C
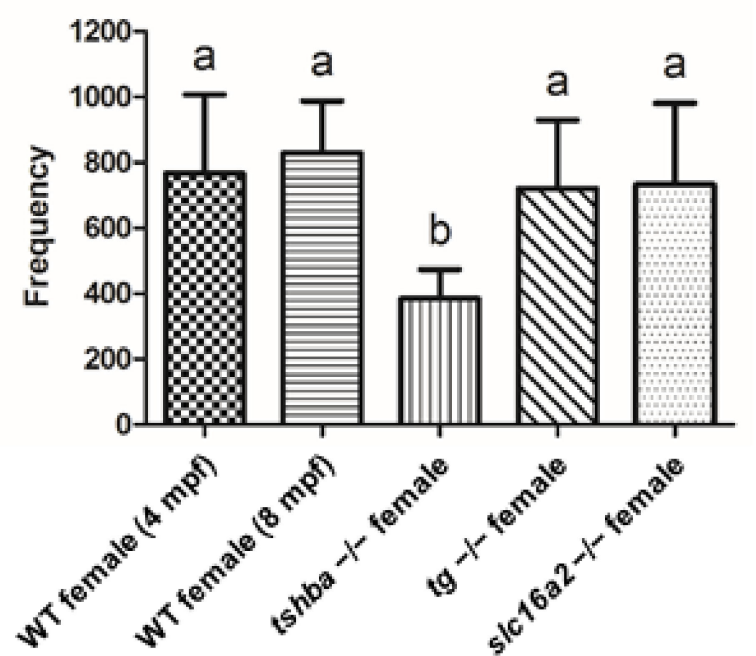

B
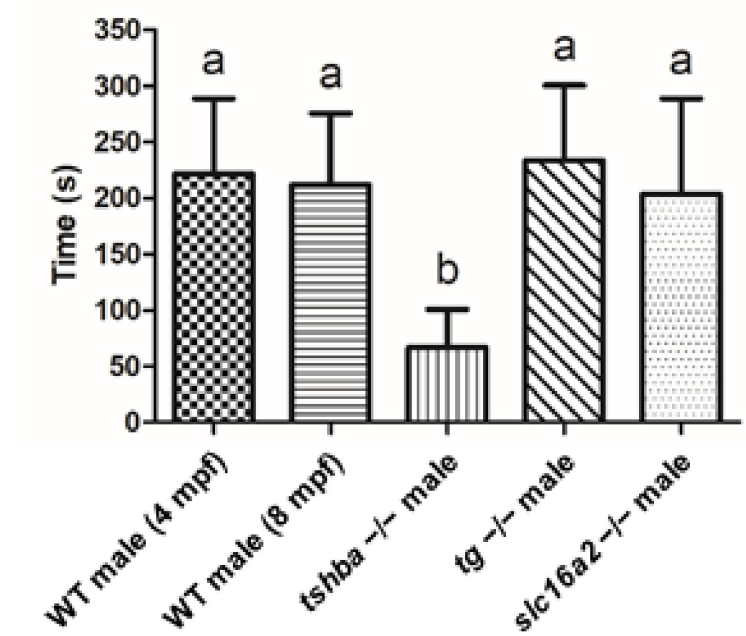

D

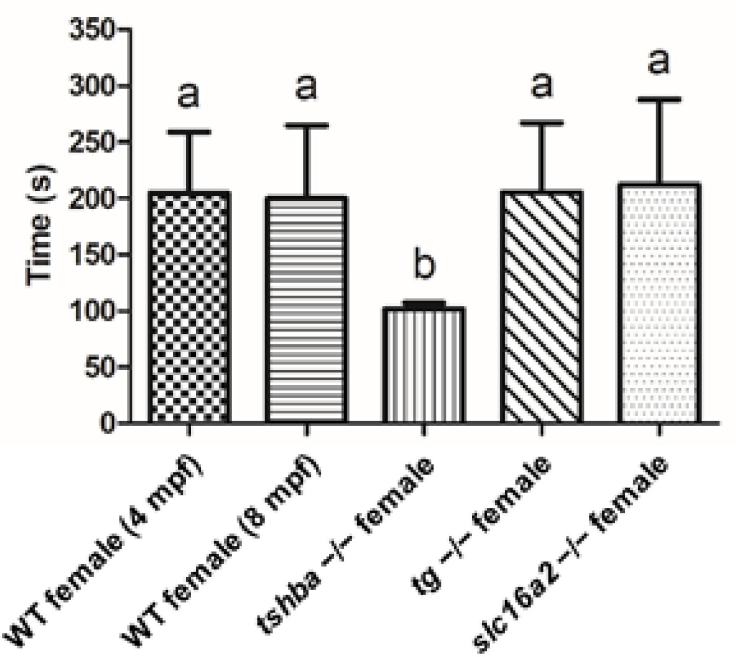

Figure 10. Reproductive behavior analyses in wild-type control fish and tshba, tg, and slc16a2 mutant zebrafish. (A,B) Mating behavior exhibited by wild-type female zebrafish towards the mutant male fish. Frequency (A) and duration (B) of intimate contacts are shown. (C,D) Mating behavior exhibited by wild-type male zebrafish toward the mutant female fish. Frequency (C) and duration (D) of intimate contacts are shown. Measurements were taken from wild-type control males ( 4 and $8 \mathrm{mpf})$ and females (4 and $8 \mathrm{mpf})$, $t g$ mutant males (4 mpf) and females (4 mpf), slc16a2 mutant males (4 mpf) and females (4 mpf), and tshba mutant males $(8 \mathrm{mpf})$ and females $(8 \mathrm{mpf}) . \mathrm{n}=3$ per group. $\mathrm{a}-\mathrm{b}$, different superscripts in the same column indicate significant differences $(p<0.05)$.

\section{Discussion}

The life cycle of teleost fish and anuran amphibians can be divided into the following five stages: zygote, embryo, larva, juvenile, and adult [41]. During amphibian metamorphosis, many TH-dependent morphological changes occur and require a gradual increase in plasma TH levels from very low in pre-metamorphic tadpoles to peak levels at the climax stages. Towards the end of metamorphosis, TH plasma levels decrease [41,42]. This amphibian metamorphosis is generally most prevalent during LTJT [43]. Many teleosts do not show dramatic changes in morphology from the larval to the juvenile stage. However, TH signaling may be necessary for the proper developmental remodeling process in zebrafish. Originally, the role of THs in zebrafish development was studied using goitrogen treatments [44-46], which biologically block TH synthesis in thyrocytes and induce the hypothyroid state. The conclusions of the LTJT studies with goitrogen treatments can 
be confusing as the chemicals used in these studies also generate risks due to toxicity associated with non-TH-related side effects [47]. Regarding the functions of endogenous TH signaling, some studies have been conducted that introduce antisense morpholino oligonucleotides (MOs) targeting certain TH-related molecules [48-51]. The phenotype with decreased body length and weight, delayed swim bladder inflation, and reduced motility has been analyzed [47]. However, gene silencing via MO experiments limits the elucidation of the functional studies to stages prior to $6 \mathrm{dpf}$ in zebrafish development, which is not extended to the LTJT period. The T3:T4 ratio, which represents monodeiodinase activity, peaks at $14 \mathrm{dpf}$ in zebrafish and may be critical for LTJT [41]. Recently, some genes, such as TH transporters (Slc16a2) and DIOs D1, D2, and D3, were targeted to generate zebrafish hypothyroidism models for peripheral TH functional studies. Defective locomotor activities have been observed in both slc16a2 and dio 2 mutant zebrafish, while the defects in swim bladder inflation and fertility have only been observed in dio2 mutant fish $[24,52]$. Considering the multi-analogous members and unique tissue distribution patterns of each TH transporter and DIO, the defective phenotypes observed with these models mainly involved tissue-specific or local effects [52,53]. In humans, the primary sources of reactive oxygen species production for TH synthesis are NADPH oxidases. Two NADPH oxidase genes, duox and duoxa2, have been identified in zebrafish [54]. In 2019, Chopra et al. generated duox mutant zebrafish, which could be a potential CCH model. Unfortunately, the authors did not measure the TH levels in the duox mutant fish, but noted that no detectable T4 signaling occurred in the thyroid region of the duox mutants at $5 \mathrm{dpf}$, identified via wholemount fluorescent immunohistochemistry. However, some phenotypes related to TH signaling, such as ragged fins, goiter, and infertility, have been characterized in duox mutant fish and heart defects in thro mutant fish. These prior studies did not focus on the LTJT period [26,27]. Generally, phenotypes, such as growth retardation and pigmentation defects, are commonly seen in many mutant zebrafish with deficiencies in $\mathrm{TH}$ signaling-related molecules [26,52]. Some phenotypes involved in the LTJT process, such as aSB inflation, jaw morphology, feeding behaviors, cranial ossification, and scale formation, are related to TH signaling [26,52,53,55]. However, to our knowledge, no previous studies have characterized all of these features during a suggested LTJT period based on systematic observations of a single $\mathrm{CCH}$ model.

The TSH signal plays key functions in the regulation of endogenous TH homeostasis in animals. However, TSH receptor ( $t s h r$ ) null mice have been generated that have severe defects and die within one week of weaning [56], making this model unsuitable for exploring the function of TSH signaling on LTJT. Surprisingly, no tshb null animal models, except for some identified natural tshb mutations from patients, have been reported previously. The mutation C105V in human tshb, the most common mutation that causes TSH deficiency, was first described in 1996, which causes severe signs of $\mathrm{CCH}$, including hypothermia, lethargy, muscle hypotonia, prolonged jaundice, and delayed closure fontanelles [57]. This $\mathrm{TSHb}$ mutation results from the last cysteine being replaced, which can modify the TSHb structure and deteriorate the heterodimeric TSH complex, which potentially leads to the inactivation of TSH or to its interplay with the TSHR. Patients with such a TSHb gene mutation show a severe phenotype compared to those with athyreosis [9]. Based on the identified fish tsh $b$ genes, most of the teleost TSH $\beta$ proteins ranged in size from 139 to 165 AAs, with 12 conserved cysteine residues and a functional domain region and exhibited strong similarities in terms of sequences with their mammalian counterparts (Supplementary Figure S1A). Like mammalian TSH $\beta$ protein, six conserved cysteine pairs in fish TSH $\beta$ protein can form the specific structure of the glycoprotein hormone, including the seat-belt structure, which wraps around the GSU $\alpha$ protein domain to form a stable heterodimer structure, thereby forming the TSH complex [58]. In the present study, a tshba-mutant zebrafish line was generated. A 5 bp deletion in the third exon of the zebrafish tshba locus resulted in a premature stop codon in the putative mutant Tshba protein. This protein may deteriorate the formation of the stable heterodimer TSH protein due to the absence of the last $\mathrm{Cys}$ of the 12 conserved Cys sites and a damaged seat-belt structure. Compared with 
their wild-type control siblings, elevated tshba mRNA (mutant form) but not tshbb mRNA in our homozygous tshba mutant was observed. Besides, the reduced transcriptional levels of $t g, t p o$, and slc5a5 and protein levels of TG have been recorded in tshba mutants compared with those of the control fish. The results of this study indicate that thyroid dyshormonogenesis is caused by the Tshba mutation and the effects of compensation of the impaired $\mathrm{TH}$ production via Tshba in the tshba mutant, but not via the $t s h b b$ in zebrafish. Since both adult males and females of homozygous tshba mutant fish were infertile, all fish used in our study were obtained from the mating of heterozygous tshba mutant parents. Thus, the effects of the maternal TSH in tshba mutant embryos cannot be excluded. Consistent with the results of previous studies regarding zebrafish thyroid development [59], tshba was first expressed between 28 and $32 \mathrm{hpf}$ in the pituitary [60]. The co-expression of tshb and $g s u$ in mutants was detected at $48 \mathrm{hpf}$, indicating the initiation of differentiated thyrotropes. No significant difference in TH levels between tshba mutants and wild-type controls was observed prior to the $20 \mathrm{dpf}$ stage, although there was a significant reduction in TG levels in the tshba mutant at $5 \mathrm{dpf}$. This suggests that TH synthesis may not be dependent on the autonomous synthesis of TSH during the early developmental stages. The significantly decreased TH levels were only detected up until 20 (T4) and 25 (T3) dpf in tshba mutant fish (Figure 1L,M), which coincides with the critical period for LTJT. In mice, TSHR may exhibit the constitutive basal signaling activity responsible for a minimal level of $\mathrm{TH}$ production [9]. If this is the case in zebrafish, it is possible that the basal signaling responsible for minimal $\mathrm{TH}$ production and active thyroid hormonogenesis, which are needed to promote critical developmental remodeling, such as LTJT, escalate endogenous TH production via TSH signaling.

In the state of hypothyroidism, TSHR null mice were severely runted and wasted during the pre-weaning period and died within one-week post-weaning [56]. Growth retardation was also exhibited in duox null zebrafish at three months of age [26]. The somatic growth retardation of our tshba mutant fish could only be distinguished from their wild-type control siblings after $35 \mathrm{dpf}$ (Figure 2D). Thus, all morphological and behavioral features of the tshba mutant fish were investigated thoroughly during the post-embryonic stages prior to $35 \mathrm{dpf}$. Previous studies based on easily identified external morphological traits (e.g., pigment pattern and fin morphology) have suggested that the majority of zebrafish reach the larval and juvenile stage at 5- and 12-mm SL [39,55]. In our study, the first altered signs detected were the delay of aSB inflation in Tshba mutant fish at their $6 \mathrm{~mm}$ SL stage. This stage occurred around $16 \mathrm{dpf}$ under our culture conditions. Significant differences in somatic growth and SL were seen after the $12 \mathrm{~mm}$ SL stage and $35 \mathrm{dpf}$ in both mutant and wild-type zebrafish. On the other hand, the period of active thyroid hormonogenesis in zebrafish coincided with the time when the significant alteration between the TH production of tshba mutant and wild-type fish was observed at 16-35 dpf (Figure 1L,M). Therefore, 6-12 mm SL and 16-35 dpf should be considered as the LTJT period for zebrafish. Previously, the initial defects in pigment patterns and aSB in $\mathrm{Tg}$ (tg: nVenus-2a-nfnB) zebrafish models were recorded at the $10 \mathrm{~mm} \mathrm{SL}$ and $5.5-8.5 \mathrm{~mm}$ SL stages, respectively [61]. In a duox-deficient zebrafish hypothyroidism model, aSB defects were observed at $21 \mathrm{dpf}$ [26]. This timing is in accordance with the results of the present study in terms of the suggested zebrafish LTJT period. Overall, beginning at the larval stage $(6.1 \mathrm{~mm} \mathrm{SL})$, we detected the phenotypes of the defective aSB inflation, SP appearance, metamorphic melanophore pattern, pelvic fin fold absorption, and cranial skeleton development in our tshba mutant fish. Reduced moving activity of the tshba mutant fish at $30 \mathrm{dpf}$ was also recorded (Figure 4D). The observed impaired features have been detected in many phenotypes of dio2-deficient zebrafish and slc16a2-morphants [52,62]. Along with the significantly reduced TH levels observed in the LTJT period of the tshba mutant fish, these results demonstrated that functional TSH signaling might be critical for stimulating active $\mathrm{TH}$ production to promote the onset of developmental remodeling of young zebrafish and account for fitness-related parameters during LTJT. 
Juvenile fish must undergo physiological rearrangements to cope with their freeswimming life during LTJT, even in a direct-developing teleost zebrafish model. TH signaling in zebrafish may play a major role in regulating aSB inflation, jaw morphology, feeding behaviors, and cranial ossification $[42,52,63,64]$. However, there have been no systemic studies, to our knowledge, that focus on the array of developmental remodeling that occurs during LTJT using a CCH model. In the present study, we demonstrated that tshba mutant zebrafish as a $\mathrm{CCH}$ model due to the impaired $\mathrm{TH}$ production dynamics display defects, including aSB inflation and cranial ossification (Figures $1 \mathrm{~L}, \mathrm{M}, 3 \mathrm{C}$ and $4 \mathrm{E}-\mathrm{L}$ ). At the end of the LTJT period, the tshba mutant fish exhibited movement defects (Figure 4D). Appropriate dynamic TH production is required for the development of zebrafish feeding mechanics via cranial ossification, which may be critical to promote their diversification into adult feeding niches [63]. In cyprinids, aSB may play an important function in hearing through its connection with the ear via the Weberian apparatus [65]. Analyses using our hypothyroidism model demonstrated differential TH dependencies of LTJT events in zebrafish via the TSH signal, and their growth retardation could be a consequence of the defects observed during LTJT (Figure 2D-G). This study established a classic CCH zebrafish model, which may be useful for studying the etiology and underlying mechanism of some human hypothyroidism diseases.

Zebrafish TG is a large, secreted glycoprotein with a predicted 2734 AA that comprises a signal peptide and I1-4 and I5-10 regions at its N terminal. Previous studies with mammalian models have indicated that region I is critical for the TG maturation process and functions involved in the regulation of cysteine or cation-dependent protease activity, as well as long-term iodide storage for iodotyrosine coupling for hormonogenesis [66]. In mammals with a large number of exons and various exonic sizes separated by introns spanning a long range in genomic DNA, Tg transcripts are very heterogeneous due to the polymorphisms. Constitutive and alternative splicing in the human $t g$ gene is complex [67]. In the present study, besides the $\mathrm{tg}$ transcript (long form), which is similar to the full-length tg mRNA deposited in GenBank, a very minor fraction of the total $t g$ transcripts was detected as the alternative splicing form of the $t g$ transcript (short form) in wild-type zebrafish (Figure $6 \mathrm{E}, \mathrm{F}$ ). The short alternative splicing $t g$ transcript form skips five complete exons (exons 3-8) with the remaining transcript in the same frame as the full-length $t g$ mRNA, suggesting a short form of TG protein with the I1-4 (293 AAs) region missing. In $\operatorname{tg}$ mutant fish, the transcriptional level of the short form alternative transcript increased significantly, especially compared with the level of full-length $t g$ transcript containing the $4 \mathrm{bp}$ missing indel (Figure 6D-F). This might be due to the compensation effects of the premature termination of the long form $\mathrm{tg}$ transcript in the -4 or $-11 \mathrm{tg}$ mutant mRNAs in these $\mathrm{tg}$ mutant fish, since the putative peptides of the -4 or $-11 \mathrm{tg}$ transcript could only be translated to a 128 AA peptide, missing almost all the functional domains in native TG protein. In humans, an estimated thyroid dyshormonogenesis incidence of approximately $1 / 100,000$ newborns has been reported due to more than 100 deleterious mutations in the $T G$ gene [14]. The typical phenotypes of thyroid dyshormonogenesis were found in our $t g$ mutant zebrafish, with significantly decreased levels of T4 and T3 production (Figure 6H-I) as well as growth retardation (Figure 8A,C-E), suggesting the poor functioning of the short TG form encoded by the $t g$ alternative splicing form without the I1-4 region.

Unlike the central functions of TSH and TG in the HPT axis, the SLC16A2 as a TH membrane transporter plays a local TH regulatory role in peripheral organs [47]. Therefore, there were much less severe defects in our slc16a2 mutant fish, compared with those observed in the tshba and $t g$ mutants. No significantly altered levels of T3 or growth retardation were recorded in the slc16a2 mutants (Figures 7F and 8B,F-H). slc16a2 mutant zebrafish have also previously been generated via the CRISPR/Cas9 technique, with the targeting site at a similar region to that of the slc16a2 mutant zebrafish targeted via the ZFN technique previously [24]. However, significantly upregulated levels of tshba were found in our slc16a2 mutants at $5 \mathrm{dpf}$, while no significant alteration of tsh expression was found in the slc16a2 mutant at $3 \mathrm{dpf}$ described previously. Significantly increased levels of 
tg expression and $\mathrm{T} 4$ at $60 \mathrm{dpf}$ were found in the slc16a2 mutants, while no information has previously been provided, to our knowledge, regarding this mutant [24].

One in eight women in the USA will develop a thyroid goiter at some point in their lifetime as a result of various factors [68]. Only a few of these incidences will be congenital goiters. Normally, the goiters can be classified as hypothyroid, euthyroid, or hyperthyroid $[11,69]$. In all cases, the roles of TSH are critical. Normally, thyroid dyshormonogenesis induces TSH production and, as a consequence, a goiter phenotype occurs in various hypothyroidism models [11]. In patients with a euthyroid goiter, the HPT axis plays a role within a relatively broad range of TSH levels to keep the TH production on track via the regulation of the thyroid gland function. Graves' disease is the most common cause of hyperthyroidism, resulting from endogenous autoantibodies in the TSHR that overactivate the receptor, thereby stimulating $\mathrm{TH}$ synthesis and secretion as well as a diffuse goiter [70]. In the mutant zebrafish models used in this study, euthyroid goiters were observed in slc16a2 mutants, with relatively normal levels of T3 without other evident phenotypes (Figures 7F, 8F,G and 9C,E). A typical phenomenon of hypothyroid goiter was found in the $t g$ mutant fish, with evident defects of $\mathrm{TH}$ production and growth (Figures 6H,I, 8A,C-E and 9B,D) similar to the defects seen in duox mutant zebrafish [26]. Significantly elevated tshba expression in both $\operatorname{tg}$ and slc16a2 mutants indicated the role of TSH in goiter formation. No goiter was observed in the $\mathrm{CCH}$ model, which further demonstrated both the essential function of TSH on the promotion of goiter and the deteriorated function of the mutated Tshba protein in the autonomous regulation of thyroid hormonogenesis in zebrafish.

Previously, reproductive dysfunction with relatively normal gamete development was observed in two hypothyroidism models: duox and dio2 zebrafish mutants [26,71]. More studies regarding dio 2 mutant fish also indicated that the sex steroid production was downregulated by dio2 deficiency [71]. However, reproductive activities in the $t g$ mutants are normal, although this seems like a typical hypothyroidism model in zebrafish. However, similar observations regarding gamete development and mating behavior in the tshba mutants, another $\mathrm{CCH}$ model, were found (Figures 5A-D and 10A-D). Impaired development of the SSCs was found in both genders of tshba mutant fish (Figure 5E-P). In our previous study with cyp17a1-deficient zebrafish, it was demonstrated that the levels of testosterone were critical to SSC development [72]. However, no significant alterations of testosterone levels in adult $t s h b a, t g$, and slc16a2 mutants have been found (Supplementary Figure S4), which is different from the observations of the adult dio2-deficient zebrafish [71]. Based on the observations from our two CCH models, the tshba mutants exhibit defective LTJT features, such as a delay in the inflation of the aSB, but the $t g$ mutants do not. By comparing the dynamic TH production patterns between tshba and tg mutants, it was found that an earlier significant decrease in T3 levels occurred in the tshba mutant compared to the $\operatorname{tg}$ mutant. This might suggest that the early alteration of T3 levels is critical for the proper development of mating behavior, and this behavior is not related with the decreased levels of steroid hormone in hyperthyroidism zebrafish models (Supplementary Figure S4). Although no information regarding the beginning of the significantly decreased $\mathrm{TH}$ levels in duox and dio2 mutants is available from previous studies [26,71], it is noteworthy that both defects of mating behavior and inflation of aSB occurred in duox, dio2, and tshba mutants (Figures 3-5 and 10) [26,71], but neither defect were seen in $t g$ mutants (Figure 10 and Figure S3). This might suggest the possible connection between the LTJT and SSC development in zebrafish.

Teleosts undergo certain post-embryonic metamorphic transitions. The present study demonstrated systematic analyses on the justification of the LTJT period and the endocrine regulation of the major features that occur during the key developmental remodeling processes of LTJT in zebrafish, with the tshba mutant model. Our three thyroid disorder models also provided various goiter models, which further justify the essential roles of TSH involved in zebrafish goiter development. Intriguingly, on combining our observations on $t s h b a, t g$, and slc16a2 mutants and previous reports on two other hyperthyroidism zebrafish 
models, duox and dio2, the involvement of TH signaling in both LTJT, and SSC development can be found. This study verifies the critical function of TSH signaling on promoting LTJT in zebrafish, which is analogous to the metamorphosis of anurans and provides important insights into the evolution of animal LTJT (or metamorphosis) and the identification of the key diversifications of physiology, behavior, and morphological features, and possibly includes SSC formation during the teleost LTJT period. More subsequent investigations are needed for the regulatory mechanisms of TH signaling in the somatic growth and SSC formation of our hyperthyroidism teleost models.

Supplementary Materials: The following are available online at https:/ / www.mdpi.com/article/10 .3390 / cells10081984/s1, Figure S1. Comparison of the protein sequence TSHb subunits, Figure S2. Histological features of the thyroid gland in tshba mutant zebrafish, Figure S3. No evident defects during larval-to-juvenile transition were observed in $t g$ or slc16a2 mutant zebrafish, Figure S4. No evident changes in testosterone content in the gonads of all three mutant fish types, Table S1. Primers used for PCR reaction, Table S2. The primers used for the amplification of $t g$ alternative short transcripts.

Author Contributions: Z.Y. and J.S. conceived and designed the analysis. X.C. generated the tshbamutant zebrafish model. J.S. generated the $t g$ - and slc16a2-mutant zebrafish models. J.S. and Y.L. carried out the experiments and acquired data. G.Z., C.S., Q.L., X.J. and J.H. contributed to the interpretation of the results. Z.Y., G.Z. and J.S. drafted and revised the paper. All authors have read and agreed to the published version of the manuscript.

Funding: This work was supported by the National Key Research and Development Program of China (2018YFA0801000 to Q.L.), the National Natural Science Foundation of China (No. 31530077 to Z.Y. and No. 31972779 to G.Z.), the State Key Laboratory of Freshwater Ecology and Biotechnology (2019FBZ05 to Z.Y.), and the Key Science and Technology Program of Henan Province (Grant No. 212102310667 to X.C.).

Institutional Review Board Statement: The study was conducted in accordance with the Guiding Principles for the Care and Use of Laboratory Animals and were approved by the Institute of Hydrobiology, Chinese Academy of Sciences (Approval ID: IHB2013724).

Informed Consent Statement: Not applicable.

Data Availability Statement: Not applicable.

Conflicts of Interest: The authors declare that there is no conflict of interest that could be perceived as prejudicing the impartiality of the research reported.

\section{References}

1. Laudet, V. The Origins and Evolution of Vertebrate Metamorphosis. Curr. Biol. 2011, 21, R726-R737. [CrossRef]

2. Dardente, H.; Hazlerigg, D.G.; Ebling, F.J.P. Thyroid Hormone and Seasonal Rhythmicity. Front. Endocrinol. 2014, 5, 19. [CrossRef]

3. Mullur, R.; Liu, Y.-Y.; Brent, G.A. Thyroid Hormone Regulation of Metabolism. Physiol. Rev. 2014, 94, 355-382. [CrossRef] [PubMed]

4. Williams, G.R. Role of Thyroid Hormone Receptor- $\alpha 1$ in Endochondral Ossification. Endocrinology 2014, 155, 2747-2750. [CrossRef] [PubMed]

5. Ji, C.; Jin, X.; He, J.; Yin, Z. Use of tsh beta:Egfp transgenic zebrafish as a rapid in vivo model for assessing thyroid-disrupting chemicals. Toxicol. Appl. Pharmacol. 2012, 262, 149-155. [CrossRef]

6. Tu, W.; Xu, C.; Lu, B.; Lin, C.; Wu, Y.; Liu, W. Acute exposure to synthetic pyrethroids causes bioconcentration and disruption of the hypothalamus-pituitary-thyroid axis in zebrafish embryos. Sci. Total Environ. 2016, 542, 876-885. [CrossRef]

7. Kim, P.S.; Lee, J.; Jongsamak, P.; Menon, S.; Li, B.; Hossain, S.A.; Bae, J.-H.; Panijpan, B.; Arvan, P. Defective Protein Folding and Intracellular Retention of Thyroglobulin-R19K Mutant as a Cause of Human Congenital Goiter. Mol. Endocrinol. 2008, 22, 477-484. [CrossRef]

8. Friesema, E.C.; Grueters, A.; Biebermann, H.; Krude, H.; von Moers, A.; Reeser, M.; Barrett, T.; Mancilla, E.E.; Svensson, J.; Kester, M.H.; et al. Association between mutations in a thyroid hormone transporter and severe X-linked psychomotor retardation. Lancet 2004, 364, 1435-1437. [CrossRef]

9. Kalveram, L.; Kleinau, G.; Szymanska, K.; Scheerer, P.; Rivero-Mueller, A.; Grueters-Kieslich, A.; Biebermann, H. The pathogenic tsh beta-subunit variant c105vfs114x causes a modified signaling profile at tshr. Int. J. Mol. Sci. 2019, 20, 5564. [CrossRef] 
10. Arturi, F.; Chiefari, E.; Tumino, S.; Russo, D.; Squatrito, S.; Chazenbalk, G.; Persani, L.; Rapoport, B.; Filetti, S. Similarities and differences in the phenotype of members of an Italian family with hereditary non-autoimmune hyperthyroidism associated with an activating TSH receptor germline mutation. J. Endocrinol. Investig. 2002, 25, 696-701. [CrossRef]

11. Böttcher, Y.; Eszlinger, M.; Tönjes, A.; Paschke, R. The genetics of euthyroid familial goiter. Trends Endocrinol. Metab. 2005, 16, 314-319. [CrossRef] [PubMed]

12. Ohye, H.; Fukata, S.; Hishinuma, A.; Kudo, T.; Nishihara, E.; Ito, M.; Kubota, S.; Amino, N.; Ieiri, T.; Kuma, K.; et al. A Novel Homozygous Missense Mutation of the Dual Oxidase 2 (DUOX2) Gene in an Adult Patient with Large Goiter. Thyroid 2008, 18, 561-566. [CrossRef]

13. Ono, E.; Ariga, M.; Oshima, S.; Hayakawa, M.; Imai, M.; Ochiai, Y.; Mochizuki, H.; Namba, N.; Ozono, K.; Miyata, I. Three novel mutations of the mct8 (slc16a2) gene: Individual and temporal variations of endocrinological and radiological features. Clin. Pediatric Endocrinol. 2016, 25, 23-35. [CrossRef]

14. Siffo, S.; Adrover, E.; Citterio, C.E.; Miras, M.B.; Balbi, V.A.; Chiesa, A.; Weill, J.; Sobrero, G.; González, V.G.; Papendieck, P.; et al. Molecular analysis of thyroglobulin mutations found in patients with goiter and hypothyroidism. Mol. Cell. Endocrinol. 2018, 473, 1-16. [CrossRef]

15. Spitzweg, C.; Morris, J.C. Genetics and phenomics of hypothyroidism and goiter due to NIS mutations. Mol. Cell. Endocrinol. 2010, 322, 56-63. [CrossRef] [PubMed]

16. MacKenzie, D.S.; Jones, R.A.; Miller, T.C. Thyrotropin in teleost fish. Gen. Comp. Endocrinol. 2009, 161, 83-89. [CrossRef]

17. Lee, J.; Arvan, P. Repeat Motif-containing Regions within Thyroglobulin. J. Biol. Chem. 2011, 286, 26327-26333. [CrossRef]

18. Mizokami, I.; Fukata, S.; Kogai, T.; Hishinuma, A.; Hamada, K.; Maruta, T.; Higashi, K.; Tajiri, J. Congenital primary hypothyroidism with the homozygous nonsense mutation p.K1374*in the thyroglobulin gene and a normal-sized thyroid gland on levothyroxine replacement. Intern. Med. 2019, 58, 2669-2673. [CrossRef]

19. Sato, A.; Abe, K.; Yuzuriha, M.; Fujii, S.; Takahashi, N.; Hojo, H.; Teramoto, S.; Aoyama, H. A novel mutation in the thyroglobulin gene that causes goiter and dwarfism in Wistar Hannover GALAS rats. Mutat. Res. Mol. Mech. Mutagen. 2014, 762, 17-23. [CrossRef]

20. Holzer, G.; Morishita, Y.; Fini, J.-B.; Lorin, T.; Gillet, B.; Hughes, S.; Tohmé, M.; Deléage, G.; Demeneix, B.; Arvan, P.; et al. Thyroglobulin Represents a Novel Molecular Architecture of Vertebrates. J. Biol. Chem. 2016, 291, 16553-16566. [CrossRef] [PubMed]

21. Zhang, S.; Guo, X.; Lu, S.; Sang, N.; Li, G.; Xie, P.; Liu, C.; Zhang, L.; Xing, Y. Exposure to PFDoA causes disruption of the hypothalamus-pituitary-thyroid axis in zebrafish larvae. Environ. Pollut. 2018, 235, 974-982. [CrossRef]

22. Dumitrescu, A.M.; Liao, X.-H.; Weiss, R.E.; Millen, K.; Refetoff, S. Tissue-Specific Thyroid Hormone Deprivation and Excess in Monocarboxylate Transporter (Mct) 8-Deficient Mice. Endocrinology 2006, 147, 4036-4043. [CrossRef] [PubMed]

23. Trajkovic, M.; Visser, T.J.; Mittag, J.; Horn, S.; Lukas, J.; Darras, V.M.; Raivich, G.; Bauer, K.; Heuer, H. Abnormal thyroid hormone metabolism in mice lacking the monocarboxylate transporter. J. Clin. Investig. 2007, 117, 627-635. [CrossRef] [PubMed]

24. Zada, D.; Tovin, A.; Lerer-Goldshtein, T.; Vatine, G.; Appelbaum, L. Altered Behavioral Performance and Live Imaging of Circuit-Specific Neural Deficiencies in a Zebrafish Model for Psychomotor Retardation. PLoS Genet. 2014, 10, e1004615. [CrossRef] [PubMed]

25. Admati, I.; Wasserman-Bartov, T.; Tovin, A.; Rozenblat, R.; Blitz, E.; Zada, D.; Lerer-Goldshtein, T.; Appelbaum, L. Neural Alterations and Hyperactivity of the Hypothalamic-Pituitary-Thyroid Axis in Oatp1c1 Deficiency. Thyroid 2020, 30, 161-174. [CrossRef]

26. Chopra, K.; Ishibashi, S.; Amaya, E. Zebrafish duox mutations provide a model for human congenital hypothyroidism. Biol. Open 2019, 8, bio037655. [CrossRef]

27. Han, C.R.; Holmsen, E.; Carrington, B.; Bishop, K.; Zhu, Y.J.; Starost, M.; Meltzer, P.; Sood, R.; Liu, P.; Cheng, S.-Y. Generation of Novel Genetic Models to Dissect Resistance to Thyroid Hormone Receptor $\alpha$ in Zebrafish. Thyroid 2020, 30, 314-328. [CrossRef]

28. Westerfield, M. The Zebrafish Book. A Guide for the Laboratory Use of Zebrafish (danio rerio), 4th ed.; University of Oregon Press: Eugene, OR, USA, 2000.

29. Neff, K.L.; Argue, D.P.; Ma, A.C.; Lee, H.B.; Clark, K.J.; Ekker, S.C. Mojo Hand, a TALEN design tool for genome editing applications. BMC Bioinform. 2013, 14, S8. [CrossRef]

30. Cermak, T.; Doyle, E.L.; Christian, M.; Wang, L.; Zhang, Y.; Schmidt, C.; Baller, J.A.; Somia, N.V.; Bogdanove, A.J.; Voytas, D. Efficient design and assembly of custom TALEN and other TAL effector-based constructs for DNA targeting. Nucleic Acids Res. 2011, 39, e82. [CrossRef]

31. Mali, P.; Yang, L.; Esvelt, K.; Aach, J.; Güell, M.; DiCarlo, J.; Norville, J.; Church, G.M. RNA-Guided Human Genome Engineering via Cas9. Science 2013, 339, 823-826. [CrossRef]

32. Vanleuven, A.J.; Park, S.; Menke, D.B.; Lauderdale, J.D. A PAGE screening approach for identifying CRISPR-Cas9-induced mutations in zebrafish. Biotechniques 2018, 64, 275-278. [CrossRef] [PubMed]

33. Peng, X.; Shang, G.; Wang, W.; Chen, X.; Lou, Q.; Zhai, G.; Li, D.; Du, Z.; Ye, Y.; Jin, X.; et al. Fatty acid oxidation in zebrafish adipose tissue is promoted by 1 alpha,25(oh)(2)d-3. Cell Rep. 2017, 19, 1444-1455. [CrossRef] [PubMed]

34. Thienpont, B.; Tingaud-Sequeira, A.; Prats, E.; Barata, C.; Babin, P.J.; Raldúa, D. Zebrafish Eleutheroembryos Provide a Suitable Vertebrate Model for Screening Chemicals that Impair Thyroid Hormone Synthesis. Environ. Sci. Technol. 2011, 45, 7525-7532. [CrossRef] 
35. Bradford, M.M. A novel method for protein estimation assay using brilliant blue g. Anal. Biochem. 1976, 72, 248-254. [CrossRef]

36. Parichy, D.M.; Elizondo, M.R.; Mills, M.G.; Gordon, T.N.; Engeszer, R.E. Normal table of postembryonic zebrafish development: Staging by externally visible anatomy of the living fish. Dev. Dyn. 2009, 238, 2975-3015. [CrossRef]

37. De Angelis, M.; Giesert, F.; Finan, B.; Clemmensen, C.; Müller, T.D.; Vogt-Weisenhorn, D.; Tschöp, M.H.; Schramm, K.-W. Determination of thyroid hormones in mouse tissues by isotope-dilution microflow liquid chromatography-mass spectrometry method. J. Chromatogr. B 2016, 1033-1034, 413-420. [CrossRef]

38. Bussy, U.; Chung-Davidson, Y.W.; Li, K.; Fissette, S.D.; Buchinger, E.G.; Li, W.M. A validated lc-ms/ms method for thyroid hormone determination in sea lamprey (petromyzon marinus) plasma, gill, kidney and liver. J. Chromatogr. B 2017, 1041, 77-84. [CrossRef] [PubMed]

39. Singleman, C.; Holtzman, N.G. Growth and Maturation in the Zebrafish, Danio Rerio: A Staging Tool for Teaching and Research. Zebrafish 2014, 11, 396-406. [CrossRef]

40. Aruldhas, M.; Valivullah, H.; Srinivasan, N.; Govindarajulu, P. Role of thyroid on testicular lipids in prepubertal, pubertal and adult rats. I. Hyperthyroidism. Biochim. Biophys. Acta (BBA) Gen. Subj. 1986, 881, 462-469. [CrossRef]

41. Chang, J.; Wang, M.; Gui, W.; Zhao, Y.; Yu, L.; Zhu, G. Changes in Thyroid Hormone Levels during Zebrafish Development. Zool. Sci. 2012, 29, 181-184. [CrossRef] [PubMed]

42. Porazzi, P.; Calebiro, D.; Benato, F.; Tiso, N.; Persani, L. Thyroid gland development and function in the zebrafish model. Mol. Cell. Endocrinol. 2009, 312, 14-23. [CrossRef] [PubMed]

43. Sachs, L.M.; Shi, Y.-B. Targeted chromatin binding and histone acetylation in vivo by thyroid hormone receptor during amphibian development. Proc. Natl. Acad. Sci. USA 2000, 97, 13138-13143. [CrossRef]

44. Schmidt, F; Braunbeck, T. Alterations along the Hypothalamic-Pituitary-Thyroid Axis of the Zebrafish (Danio rerio) after Exposure to Propylthiouracil. J. Thyroid Res. 2011, 2011, 1-17. [CrossRef]

45. Stinckens, E.; Vergauwen, L.; Ankley, G.T.; Blust, R.; Darras, V.M.; Villeneuve, D.L.; Witters, H.; Volz, D.C.; Knapen, D. An AOPbased alternative testing strategy to predict the impact of thyroid hormone disruption on swim bladder inflation in zebrafish. Aquat. Toxicol. 2018, 200, 1-12. [CrossRef] [PubMed]

46. Stinckens, E.; Vergauwen, L.; Schroeder, A.L.; Maho, W.; Blackwell, B.; Witters, H.; Blust, R.; Ankley, G.T.; Covaci, A.; Villeneuve, D.L.; et al. Impaired anterior swim bladder inflation following exposure to the thyroid peroxidase inhibitor 2mercaptobenzothiazole part II: Zebrafish. Aquat. Toxicol. 2016, 173, 204-217. [CrossRef]

47. Vancamp, P.; Houbrechts, A.M.; Darras, V.M. Insights from zebrafish deficiency models to understand the impact of local thyroid hormone regulator action on early development. Gen. Comp. Endocrinol. 2019, 279, 45-52. [CrossRef] [PubMed]

48. De Vrieze, E.; Van De Wiel, S.M.W.; Zethof, J.; Flik, G.; Klaren, P.; Arjona, F. Knockdown of Monocarboxylate Transporter 8 (mct8) Disturbs Brain Development and Locomotion in Zebrafish. Endocrinology 2014, 155, 2320-2330. [CrossRef] [PubMed]

49. Heijlen, M.; Houbrechts, A.M.; Bagci, E.; Van Herck, S.L.; Kersseboom, S.; Esguerra, C.; Blust, R.; Visser, T.J.; Knapen, D.; Darras, V.M. Knockdown of Type 3 Iodothyronine Deiodinase Severely Perturbs Both Embryonic and Early Larval Development in Zebrafish. Endocrinology 2014, 155, 1547-1559. [CrossRef] [PubMed]

50. Houbrechts, A.M.; Vergauwen, L.; Bagci, E.; Van Houcke, J.; Heijlen, M.; Kulemeka, B.; Hyde, D.R.; Knapen, D.; Darras, V.M. Deiodinase knockdown affects zebrafish eye development at the level of gene expression, morphology and function. Mol. Cell. Endocrinol. 2016, 424, 81-93. [CrossRef]

51. Opitz, R.; Maquet, E.; Zoenen, M.; Dadhich, R.; Costagliola, S. TSH Receptor Function Is Required for Normal Thyroid Differentiation in Zebrafish. Mol. Endocrinol. 2011, 25, 1579-1599. [CrossRef]

52. Houbrechts, A.M.; Delarue, J.; Gabriëls, I.J.; Sourbron, J.; Darras, V.M. Permanent Deiodinase Type 2 Deficiency Strongly Perturbs Zebrafish Development, Growth, and Fertility. Endocrinology 2016, 157, 3668-3681. [CrossRef] [PubMed]

53. Silva, N.; Louro, B.; Trindade, M.; Power, D.; Campinho, M.A. Transcriptomics reveal an integrative role for maternal thyroid hormones during zebrafish embryogenesis. Sci. Rep. 2017, 7, 16657. [CrossRef]

54. Trubiroha, A.; Gillotay, P.; Giusti, N.; Gacquer, D.; Libert, F.; Lefort, A.; Haerlingen, B.; De Deken, X.; Opitz, R.; Costagliola, S. A Rapid CRISPR/Cas-based Mutagenesis Assay in Zebrafish for Identification of Genes Involved in Thyroid Morphogenesis and Function. Sci. Rep. 2018, 8, 5647. [CrossRef] [PubMed]

55. Brown, D.D. The role of thyroid hormone in zebrafish and axolotl development. Proc. Natl. Acad. Sci. USA 1997, 94, 13011-13016. [CrossRef] [PubMed]

56. Marians, R.C.; Ng, L.; Blair, H.C.; Unger, P.; Graves, P.N.; Davies, T.F. Nonlinear partial differential equations and applications: Defining thyrotropin-dependent and -independent steps of thyroid hormone synthesis by using thyrotropin receptor-null mice. Proc. Natl. Acad. Sci. USA 2002, 99, 15776-15781. [CrossRef]

57. Medeiros-Neto, G.; Herodotou, D.T.; Rajan, S.; Kommareddi, S.; Lacerda, L.; Sandrini, R.; Boguszewski, M.C.; Hollenberg, A.N.; Radovick, S.; Wondisford, F.E. A circulating, biologically inactive thyrotropin caused by a mutation in the beta subunit gene. J. Clin. Investig. 1996, 97, 1250-1256. [CrossRef]

58. Szkudlinski, M.W.; Fremont, V.; Ronin, C.; Weintraub, B.D. Thyroid-Stimulating Hormone and Thyroid-Stimulating Hormone Receptor Structure-Function Relationships. Physiol. Rev. 2002, 82, 473-502. [CrossRef]

59. Tonyushkina, K.N.; Shen, M.-C.; Ortiz-Toro, T.; Karlstrom, R.O. Embryonic exposure to excess thyroid hormone causes thyrotrope cell death. J. Clin. Investig. 2013, 124, 321-327. [CrossRef] 
60. Alt, B.; Reibe, S.; Feitosa, N.M.; Elsalini, O.A.; Wendl, T.; Rohr, K.B. Analysis of origin and growth of the thyroid gland in zebrafish. Dev. Dyn. 2006, 235, 1872-1883. [CrossRef]

61. McMenamin, S.; Bain, E.J.; McCann, A.E.; Patterson, L.B.; Eom, D.S.; Waller, Z.P.; Hamill, J.C.; Kuhlman, J.A.; Eisen, J.S.; Parichy, D.M. Thyroid hormone-dependent adult pigment cell lineage and pattern in zebrafish. Science 2014, 345, $1358-1361$. [CrossRef]

62. Campinho, M.A.; Saraiva, J.; Florindo, C.; Power, D. Maternal Thyroid Hormones Are Essential for Neural Development in Zebrafish. Mol. Endocrinol. 2014, 28, 1136-1149. [CrossRef] [PubMed]

63. Galindo, D.; Sweet, E.; DeLeon, Z.; Wagner, M.; DeLeon, A.; Carter, C.; McMenamin, S.; Cooper, W.J. Thyroid hormone modulation during zebrafish development recapitulates evolved diversity in danionin jaw protrusion mechanics. Evol. Dev. 2019, 21, 231-246. [CrossRef] [PubMed]

64. McMenamin, S.; Carter, C.; Cooper, W.J. Thyroid Hormone Stimulates the Onset of Adult Feeding Kinematics in Zebrafish. Zebrafish 2017, 14, 517-525. [CrossRef]

65. Fay, R.R.; Popper, A.N. Acoustic Stimulation of the Ear of the Goldfish (Carassius Auratus). J. Exp. Biol. 1974, 61, 243-260. [CrossRef] [PubMed]

66. Di Jeso, B.; Arvan, P. Thyroglobulin From Molecular and Cellular Biology to Clinical Endocrinology. Endocr. Rev. 2015, 37, 2-36. [CrossRef]

67. Citterio, C.E.; Morales, C.M.; Bouhours-Nouet, N.; Machiavelli, G.A.; Bueno, E.; Gatelais, F.; Coutant, R.; Gonzalez-Sarmiento, R.; Rivolta, C.M.; Targovnik, H.M. Novel compound heterozygous thyroglobulin mutations c.745+1g > a c.7036+2t $>$ a associated with congenital goiter and hypothyroidism in a vietnamese family. Identification of a new cryptic 5 splice site in the exon 6 . Mol. Cell. Endocrinol. 2015, 404, 102-112. [CrossRef]

68. Maniakas, A.; Davies, L.; Zafereo, M.E. Thyroid disease around the world. Otolaryngol. Clin. N. Am. 2018, 51, 631-642. [CrossRef]

69. Cooper, D.S. Hyperthyroidism. Lancet 2003, 362, 459-468. [CrossRef]

70. Franklyn, J.A.; Boelaert, K. Thyrotoxicosis. Lancet 2012, 379, 1155-1166. [CrossRef]

71. Houbrechts, A.M.; Van Houcke, J.; Darras, V.M. Disruption of deiodinase type 2 in zebrafish disturbs male and female reproduction. J. Endocrinol. 2019, 241, 111-123. [CrossRef]

72. Zhai, G.; Shu, T.; Xia, Y.; Lu, Y.; Shang, G.; Jin, X.; He, J.; Nie, P.; Yin, Z. Characterization of Sexual Trait Development in cyp17a1-Deficient Zebrafish. Endocrinology 2018, 159, 3549-3562. [CrossRef] [PubMed] 